\title{
Analytical Approach of Global Mobility Support Schemes in IP-based Heterogeneous Mobile Networks
}

\author{
Younghoon Won $^{+} \cdot$ Jongpil Jeong ${ }^{+\dagger}$
}

\begin{abstract}
Mobility management of the mobile nodes and provision of seamless handover is crucial to an efficient support for the global roaming of the mobile nodes in next-generation wireless networks. Mobile IPv6 and mobility management in extended IP layer, which highly depend on traffic characteristics and user mobility models, were proposed by the IETF. Therefore, to evaluate the in-depth performance about these factors is important. Generally, the performance of IPv6-based mobility management protocol is evaluated through simulation. This paper shows the correlation between network parameters and performance metrics through numerical results, which is investigated how influence handoff latency and packet loss. And this paper uses mathematical analysis of the system parameters, such as the subnet residence time, the packet arrival rate and delay in wireless connection through the analytical framework which evaluate the performance of IPv6-based mobility management protocol.
\end{abstract}

Keywords : Mobile Management, IP-based Mobile Network, Global Roaming, Analytical Framework

\section{IP기반 이종 모바일 네트워크에서 글로벌 이동성 지원기법의 분석적 접근법}

\author{
원 영 훈 ${ }^{+}$정 종 필
}

\begin{abstract}
요 약
차세대 무선 네트워크에서 $\mathrm{MN}$ 의 글로벌 로밍을 효율적으로 지원하기 위해서는 원활한 핸드오버와 $\mathrm{MN}$ 의 이동성관리는 매우 중요하다. $\mathrm{IETF}$ 가 모바일 IPv6와 보다 확장된 IP 계층에서의 이동성관리를 제안하였지만 트래픽 특성 및 사용자의 MN에 따라 크게 좌우된다. 그러므로 이러한 요인에 관해 심도있는 성능을 평가하는 것이 중요하다. 일반적으로 IPv6 기반 이동성관리 프로토콜의 성능은 시뮬레이션을 통해 평가하 는데 본 논문에서는 IPv6 기반 이동성관리 프로토콜의 성능을 평가하는 분석 프레임워크를 제안한다. 서브넷 체류 시간, 패킷 도착률과 무선 연결 지연 등 시스템 매개변수들의 수학적 분석을 이용하여 핸드오프 지연, 패킷 손실에 대한 성능평가를 수행하고, 분석 결과를 통해 네트워 크 매개변수와 성능분석 수치간의 상관관계를 제시한다.
\end{abstract}

키워드 : 이동성 관리, IP기반의 모바일 네트워크, 글로벌 이동성 지원, 분석 프레임워크

\section{1. 서}

차세대 무선 네트워크와 $4 \mathrm{G}$ 네트워크 상에서 원활한 핸 드오프의 제공과 이동성관리는 핵심적인 주제이다. 원활한 핸드오프의 제공과 이동성관리는 원활한 이동성과 연속적 인 서비스를 제공하기 위해 중요하며 지능적이고 효율적인

※ 이 논문은 2011년도 정부(교육과학기술부)의 재원으로 한국연구재단의 기초 연구사업 지원을 받아 수행된 것임(2011-0027030).

† 준 회 원 : 성균관대학교 정보통신대학 석사과정

†† 정 회 원: 성균관대학교 산학협력단 산학협력중점교수

논문접수 : 2012년 5월 23일

수 정 일 : 1 차 2012년 8월 16 일, 2 차 2012년 9월 10일

심사완료 : 2012년 9월 11일

* Corresponding Author: Jongpil Jeong(jpjeong@skku.edu)
방법으로 구성이 되어야 한다. 그러나 서로 다른 모바일 네트워크가 중첩되는 경우의 이질감을 해소하기 위해 새로 운 아키텍쳐의 디자인, 이동성관리 프로토콜, 서비스 품질 및 확실한 보안, 빠른 무선 접속, 네트워크 프로토콜 간의 통일된 상호 연결 요소 등을 필요로 하게 되었다. 이러한 요소들로 포함하여 제안된 것이 IP(Internet Protocol)이며 이 프로토콜은 효율적인 비용과 확장성이 보장된 응용 프 로그램을 지원하기 때문에 차세대 무선 네트워크의 핵심 백본 네트워크로써 모바일 네트워크 통신의 이질감 감소와 다양한 네트워크의 컨버전스에 많은 도움이 될 것으로 예 상하였다[1].

그에 따라 IETF는 IP계층에서 모바일 이동성관리를 위한 
기본 프로토콜로 $\mathrm{MIPv} 4(\mathrm{Mobile} \mathrm{IPv} 4)$ 의 확장개념인 MIPv6(Mobile IPv6)[2]를 제안하였다. 그러나 MIPv6 프로 토콜에서는 몇 가지 단점이 발견되었는데 특히 $\mathrm{HA}$ (Home Agent)나 $\mathrm{MN}$ (Mobile Node)에서 $\mathrm{CN}$ (Correspondent Node) 이 지리적으로 멀리 위치할 때 상당한 시그널링 부하가 발 생하고 이로 인해 시그널링(Binding Massage)을 실시간으 로 전달할 때 사용자가 인지할 수 있을 정도의 핸드오프 지 연을 발생시켰고 패킷 손실의 비율이 매우 높아지는 결과를 초래하게 되었다.

그래서 MIPv6를 기반으로 한 FMIPv6(Fast Handover for MIPv6)[3]와 HMIPv6(Hierarchical MIPv6)[4]와 같은 몇 가지의 프로토콜이 제안되었고 F-HMIPv6(Fast Handover for HMIPv6)[14]와 FPMIPv6(Fast Proxy MIPv6)[20] 같은 프로토콜의 표준화를 진행하여 성능 향상을 꾀하였다. 이러 한 제안에도 불구하고 아직도 차세대 무선 네트워크 상에서 우수한 서비스 품질을 제공할 수 있는 이동성관리 프로토콜 은 복잡하고 어려운 과제로 남아있다. 이를 개선하기 위한 IPv6 기반 모바일 이동성관리 프로토콜의 성능 평가는 일반 적으로 시뮬레이션과 테스트 베드 위주로 이루어지고 있지 만[5],[6] 시뮬레이션을 통한 IPv6 기반 핸드오프 프로토콜의 성능 평가는 프로토콜간의 비교가 어렵고 작업 시나리오에 따라 결과가 크게 달라진다. 몇몇 문헌을 통해 성능분석 평 가결과를 확인 할 수 있지만 간단한 가정에 기초하고 있으 면 단점을 가진 사례도 많다. [7]은 IP 기반 이동성 프로토 콜의 효율성을 평가하고 총 시그널링 비용을 계산하기 위해 시그널링 비용과 터널링 비용 사이의 상관관계를 제안하였 지만 이는 주로 PCS(Personal Communication Systems)를 위한 위치 관리 프로토콜로 제안되었다. [8]은 IPv6 기반 이 동성 프로토콜의 핸드오프 지연에 대한 기능 몇세 및 구현 에 적합한 구조를 평가하기 위한 프로토콜을 제안하였고 [9] 는 시그널링 방출 주파수에 따라 대역폭 신호의 분석을 제 안하였지만 패킷 터널링에 의해 생성된 시그널링 오버헤드 는 고려하지 않았다. [10]은 IP 기반 셀룰러 네트워크 상에 서 HMIPv6의 성능평가를 위한 분석모델이 제안되었으나 이 모델은 대역폭에서 소비하는 데이터의 패킷 전달 비용만 을 고려하고 트래픽을 제어하는 여분의 신호 소비를 무시하 였다. [11]은 MIPv6와 FMIPv6의 시그널링 오버헤드를 비교 분석 하였지만 패킷 손실, 핸드오프 지연시간과 사용자의 이동성 모델이 조사되지 않았다.

이에 따라 [21]의 평가 기법을 이용하여 IETF에서 제안 한 다양한 IPv6 기반 이동성 프로토콜에 대해 매개변수를 통해 $\mathrm{MN}$ 이 서브넷에 거주하는 동안 생성되는 총 시그널링 비용과 핸드오프 지연시간, 패킷 손실에 따른 버퍼공간을 고려하여 포괄적인 분석을 수행하였고 이러한 분석 기준을 바탕으로 트래픽 매개변수에 따라 얻어낸 수치결과를 분석 하였다.

논문의 구성은 다음과 같다. 2장에서 관련연구를 설명하 고, 3장과 4장에서 이동성 프로토콜의 모델링과 성능평가를 수행한다. 5장에서는 본 논문의 결론을 설명한다.

\section{2. 관련 연구}

모바일 네트워크의 이동성관리는 사용자의 위치에 따른 로밍이 가능한 위치 관리 및 새로운 서브넷으로 이동할 때 그들의 연결 상태를 유지하는 핸드오버 관리가 가능해야 한 다. 그에 따른 IPv6기반의 이동성관리를 위해 제안된 몇 가 지 프로토콜을 간략하게 소개하고자 한다.

정의 : 핸드오버 또는 핸드오프는 서로 다른 네트워크 지 역 사이의 $\mathrm{MN}$ 의 움직임이다. 즉 기존의 네트워크 연결을 종료하고 새로운 연결을 획득하는 과정이다. IP 기반의 차세 대 무선 네트워크 상에서 핸드오버는 링크 (L2)계층에서의 액세스 포인트 변화와 IP 계층에서의 라우팅 변경 사항을 포함할 수 있다. 끊김 없는 핸드오버를 보장해야 효율적인 메커니즘이다. 즉 핸드오프 지연시간, 패킷 손실, 핸드오프 오류를 최소화 하고 연속적으로 서비스가 가능해야 한다.

정의 : 핸드오프 지연시간은 $\mathrm{MN}$ 이 핸드오프를 하는 동안 패킷을 보내거나 받을 수 없는 상태의 시간 간격이며 그것 은 L2와 L3 계층으로 구성되어 있다. L3 계층의 핸드오프 지연시간은 $\mathrm{MN}$ 움직임 감지, $\mathrm{IP}$ 주소 구성 및 시그널링 절 차 시간의 합으로 구성한다.

Fig. 1은 이동성 관리의 종류와 그에 대한 클래스를 나타 낸 것이다. 이동성 관리에는 호스트 기반 프로토콜과 네트 워크 기반 프로토콜 두 가지의 프로토콜로 나눌 수 있고, $\mathrm{MN}$ 이 이동하는 도메인 영역에 따라 도메인 내부의 이동은 로컬 이동성 관리, 도메인 변경이 발생하는 이동은 글로벌 이동성 관리로 분류할 수 있다.

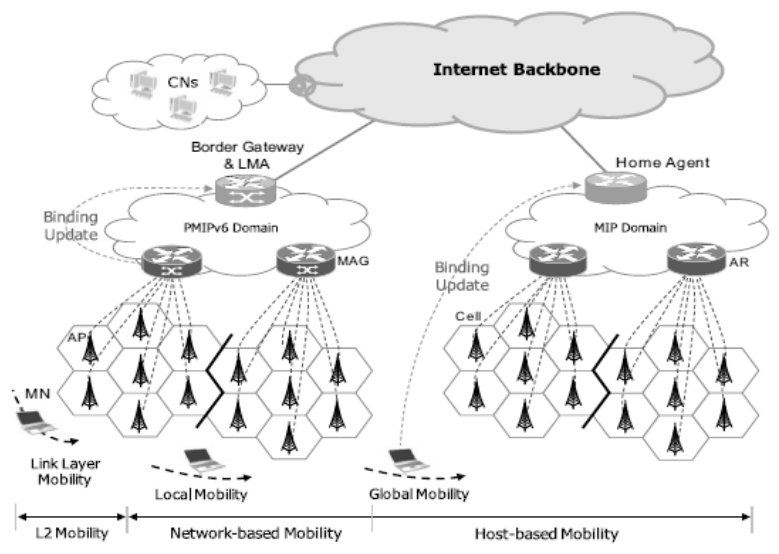

Fig. 1. Classification of mobility on the wireless network management

\subsection{MIPv6}

MIPv6(Mobile IPv6)[2]는 IP 계층에서 $\mathrm{MN}$ 의 이동성을 관 리하기 위해 제안된 프로토콜이며 $\mathrm{IP}$ 계층 상에서 $\mathrm{MN}$ 이 이 동함에도 불구하고 연결을 계속적으로 유지할 수 있도록 제 안되었다. 각 $\mathrm{MN}$ 은 항상 $\mathrm{MN}$ 이 속한 $\mathrm{HoA}$ (Home of Address) 정보를 가진다. $\mathrm{MN}$ 이 $\mathrm{HoA}$ 를 변경하게되면 해당하 
는 $\mathrm{MN}$ 의 현재 위치는 $\mathrm{CoA}\left(\mathrm{Care}^{-} \mathrm{of}\right.$ Address)에 의해 관리되 는데 이동한 위치의 인접한 라우터가 RA(Router Advertisement)패킷을 통한 RS(Router Solicitation)로 정보를 교환하여 새로 접속 가능한 라우터를 식별한다. 식별 도중 $\mathrm{CoA}$ (정보를 저장하던 저장하지 않던[12])는 $\mathrm{DAD}$ (Duplicate Address Detection)라는 프로시져를 통해 NA(Neighbor Advertisement)패킷을 통한 NS(Neighbor Solicitation)로 정 보를 교환하여 해당 링크가 중복되지 않은 고유한 링크인지 식별한다. $\mathrm{CoA}$ 의 프로시져 작업이 끝나고 $\mathrm{MN}$ 은 새로운 $\mathrm{HA}$ (Home Agent)에 시그널링(Binding Massage) 메시지 교 환을 통해 BAck(Binding Acknowledgment)을 수신하며 $\mathrm{MN}$ 은 해당 바인딩 정보를 갱신한다. 그리고 경로 최적화를 활성 화 하기 위해서 $\mathrm{MN}$ 에 대해 운영중인 모든 $\mathrm{CN}$ 들의 바인딩 프로시져를 수행한다.

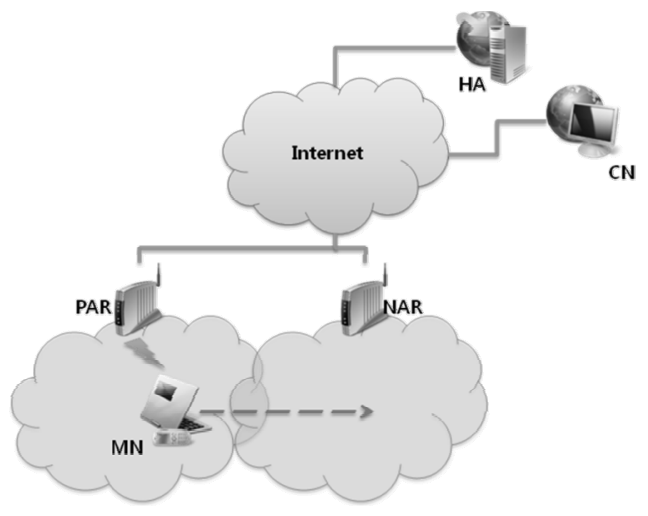

Fig. 2. MIPv6 protocol

그러나 RR(Return Routability)프로시져는 정상적이던 다 른 악의적인 $\mathrm{MN}$ 에 의해 비 정상적이던 $\mathrm{CN}$ 의 바인딩 업데 이트가 이루어지기 전에 수행되어야 한다. RR프로시져는 HoTI(Home Test Init)기능과 HoT(Home Test) 메시지 교 환으로 이루어진 HoAT(Home of Address Test)와 CoTI(Care-of Test Init)기능과 CoT(Care-of Test) 메시지 교환으로 이루어진 $\mathrm{CoAT}$ (Care-of Address Test)로 구성이 되어있다. RR 프로시져는 세션 하이잭킹을 방지하는데 도움 이 되지만 바인딩 업 데이트 프로시져 수행에 지연을 가져온 다. MIPv6의 구성도는 Fig. 2에 메시지 흐름의 순서는 Fig. 3 에서 확인 할 수 있다.

위에서 분석한대로 MIPv6는 높은 패킷 손실, 사용자가 느낄 수 있을 만큼의 핸드오프 지연 등 몇 가지 단점이 있 는 것을 알 수 있다. 또한 위와 같은 문제는 로컬 네트워크 의 이동이 아닌 글로벌 네트워크의 이동에서도 문제가 발생 한다. 두 개의 $\mathrm{MN}$ 이 동시에 이동하여 지속적으로 세션을 가지고 있을 경우 경로 최적화를 하면 문제가 발생하기 때 문이다[13].

\subsection{FMIPv6}

FMIPv6(Fast Handovers for Mobile IPv6)[3]는 MIPv6에 관해 핸드오버를 하는 동안 핸드오프 지연시간을 줄이고 서

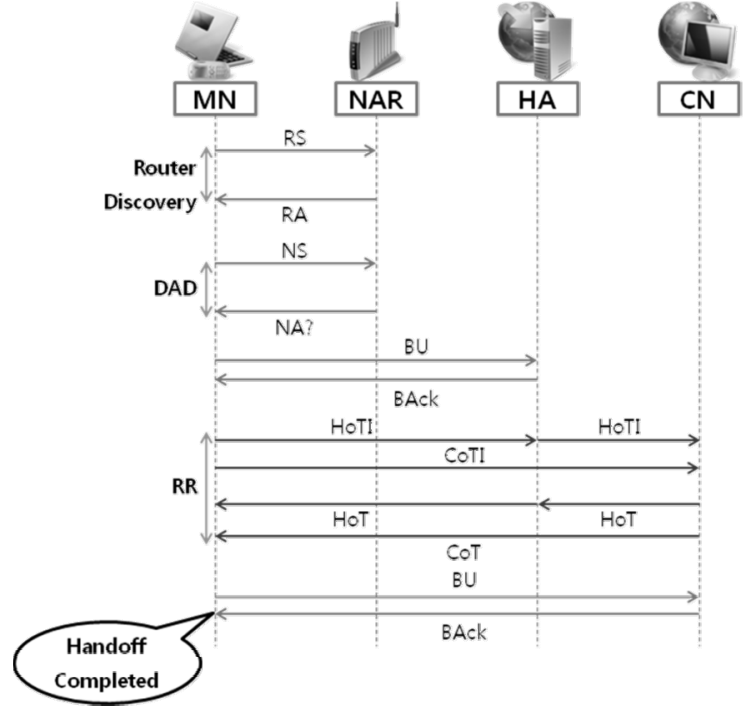

Fig. 3. Message flow diagram of the MIPv6 protocol

비스 중단을 최소화하기 위해 제안되었다. FMIPv6는 핸드 오버가 발생하면 미리 예측하거나 핸드오버를 신속하게 반 응하기 위해 L2 트리거를 사용한다. MN이 NAR(New Access Router) 방향으로의 움직임을 감지하면, L2 트리거 를 사용하여 프록시에게 $\operatorname{PrRtAdv}(\operatorname{Proxy}$ Router Advertisement) 메시지 패킷을 통한 RtSolPr(Router Solicitation for Proxy)로 정보를 교환하여 이전에 액세스 했던 라우터 PAR(Previous Access Router)의 정보와 NAR 의 대한 정보를 얻어 $\mathrm{NCoA}(\mathrm{new} \mathrm{CoA})$ 를 구성한다. 그런 다 음 $\mathrm{MN}$ 은 $\mathrm{NCoA}$ 로 $\mathrm{PCoA}$ (previous $\mathrm{CoA}$ )를 연결하기 위해 $\mathrm{PAR}$ 에 대해 $\mathrm{FBU}(\mathrm{Fast}$ Binding Update)를 보낸다. 그리고 $\mathrm{HI}$ (Handover Initiate) 메시지와 HAck(Handover Acknowledgment) 메시지를 교환하는데 있어서 실패를 방 지하기 위해 $\mathrm{NAR}$ 와 $\mathrm{PAR}$ 사이에 양방향 터널을 개설하여 라우팅을 설정한다. 그 다음 $\mathrm{MN}$ 에 미리 구성된 $\mathrm{NCoA}$ 및 양방향 터널 설립 검증에 대한 상태를 보고하는 FBAck(Fast Binding Acknowledgment) 메시지를 통해 $\mathrm{PAR}$ 은 $\mathrm{MN}$ 에게 $\mathrm{NCoA}$ 의 정보를 담아 $\mathrm{FBAcK}$ 메시지를 보 내고 $\mathrm{NAR}$ 의 링크를 통해 $\mathrm{PCoA}$ 의 정보를 담아 $\mathrm{NAR}$ 에게 $\mathrm{FBAcK}$ 메시지를 보낸다. $\mathrm{NAR}$ 의 버퍼는 $\mathrm{MN}$ 이 $\mathrm{NAR}$ 에 접 속할 때까지 패킷을 계속 버퍼링한다. 그런 다음 $\mathrm{MN}$ 은 FNA(Fast Neighbor Advertisement) 옵션을 사용하여 NAR 에게 $\mathrm{RS}$ (Router Solicitation) 메시지를 보내 새로운 링크를 생성하고 $\mathrm{NAR}$ 은 $\mathrm{MN}$ 에 버퍼링 된 패킷을 제공한다. FMIPv6의 프로토콜은 Fig. 4에서 확인 할 수 있고 Predictive 모드의 메시지 흐름 순서는 아래 Fig. 5에서 확 인 할 수 있다.

FMIPv6의 다른 모드는 Reactive 모드인데 이 모드는 $\mathrm{MN}$ 이 이미 $\mathrm{PAR}$ 에서 벗어나 $\mathrm{NAR}$ 로 접속하고 있는 단계에 서 사용되는 모드이다. 이 상태의 $\mathrm{MN}$ 은 $\mathrm{PAR}$ 가 성공적으로 $\mathrm{F}$ 시그널링을 처리했는지 알 수가 없는 상태이기 때문에 $\mathrm{FBAcK}$ 메시지를 $\mathrm{FNA}$ 를 통해 $\mathrm{NAR}$ 에게 직접 전송한다. 


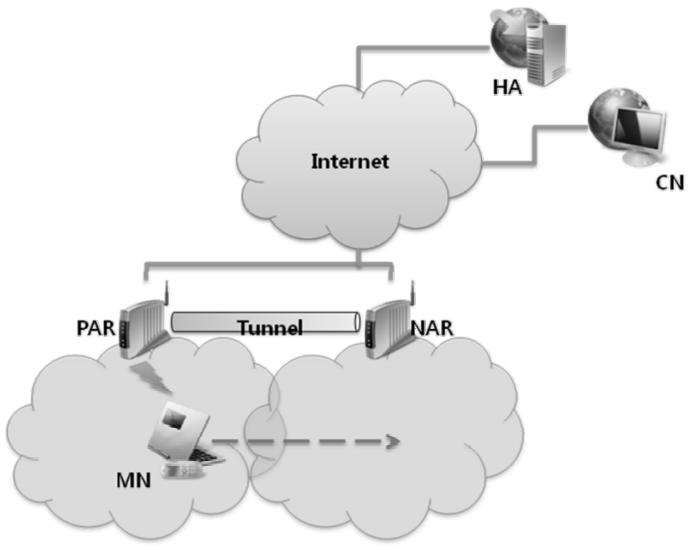

Fig. 4. FMIPv6 protocol

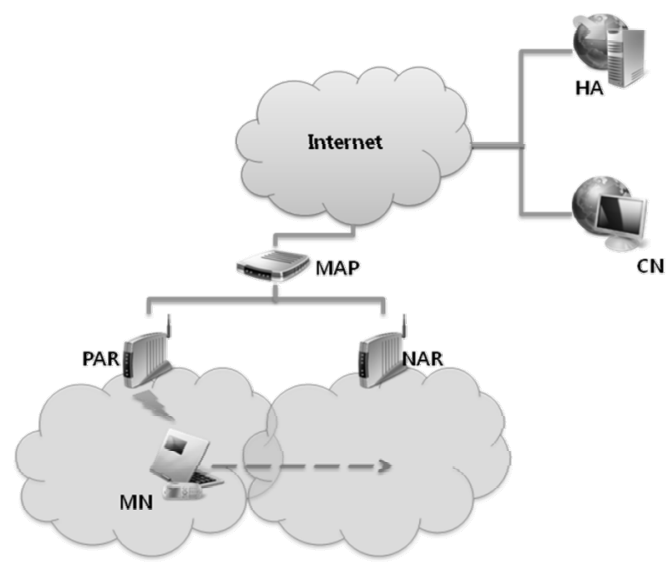

Fig. 6. HMIPv6 protocol
$\mathrm{NAR}$ 는 $\mathrm{FNA}$ 를 처리 할 때 $\mathrm{NCoA}$ 의 정보 $(\mathrm{MN}$ 이 부여 받은 $\mathrm{IP}$ 주소)가 충돌하면 수신한 정보를 버리고 다른 IP 정보를 포함한 NAAck(Neighbor Advertisement Acknowledge)를 $\mathrm{RA}$ (Router Advertisement) 메시지를 $\mathrm{MN}$ 에게 보내야 한다. 그렇지 못할 경우 NAR는 FBack에 응답할 수 있도록 $\mathrm{PAR}$ 로 $\mathrm{FBU}$ 메시지를 전송한다. 이때 $\mathrm{PAR}$ 은 $\mathrm{NAR}$ 의 링크를 통해 $\mathrm{PCoA}$ 의 정보를 담아 $\mathrm{NAR}$ 에게 $\mathrm{NCoA}$ 의 정보를 $\mathrm{PAR}$ 와 $\mathrm{NAR}$ 사이에 생성된 터널을 통해 전달하고, 그 다음 $\mathrm{NAR}$ 는 $\mathrm{MN}$ 에 해당 정보 패킷을 전송한다.

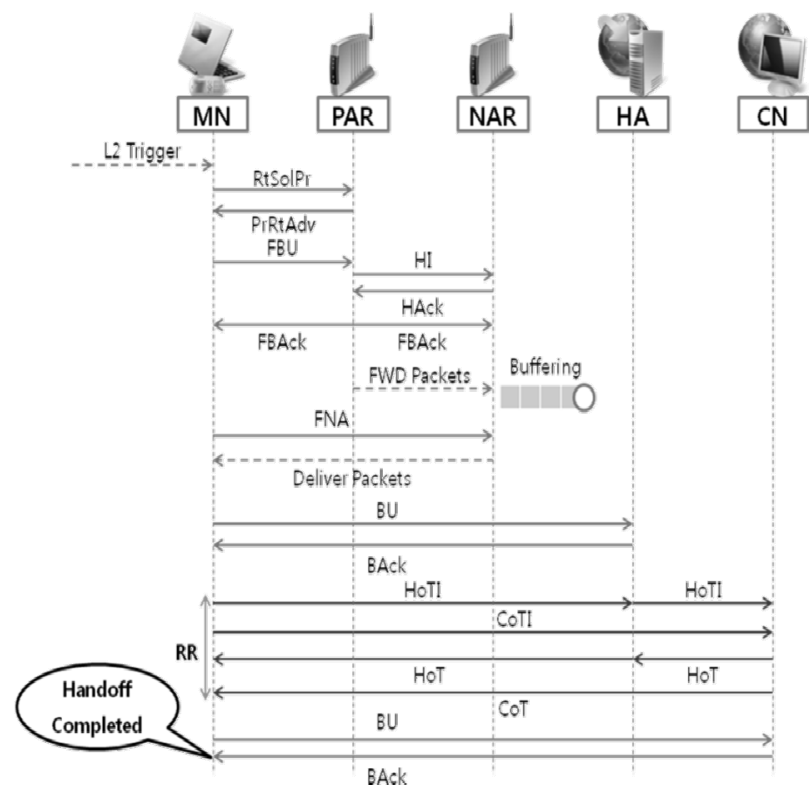

Fig. 5. Message flow diagram of the FMIPv6 protocol

\subsection{HMIPV6}

$\mathrm{MIPv} 6$ 는 $\mathrm{MN}$ 의 움직임에 관계없이 다른 서브넷의 $\mathrm{HA}$ 와 $\mathrm{CN}$ 들에게 바인딩 업데이트를 수행하는데 이는 불필요한 시 그널링 지연을 유도하는 행위이다. 이 문제를 해결하기 위 해 HMIPv6(Hierarchical Mobile IPv6)[4]는 MAP(Mobility Anchor Point)라 불리는 특별한 노드를 통해 로컬 핸드오프
를 처리하기 위해 제안되었다. MAP은 접속한 네트워크에 로컬 $\mathrm{HA}$ 의 역할을 수행하는데 MIPv6에서 외부 도메인 시 그널링의 양을 제한하고 위치 업데이트 지연시간을 줄일 수 있다. 그래서 $\mathrm{MN}$ 은 $\mathrm{MAP}$ 을 통해 $\mathrm{MAP}$ 에 속한 서브넷의 $\mathrm{RCoA}$ (Regional Care-of Address) 정보와 $\mathrm{MN}$ 이 속한 현재 위치에 해당하는 LCoA(Link Care-of Address) 정보, 두 가 지의 임시 IP주소를 구성한다.

그리고 $\mathrm{MN}$ 이 $\mathrm{MAP}$ 안의 도메인이나 $\mathrm{AN}$ (Access Network) 안에서 이동하는 동안 $\mathrm{HA}$ 나 $\mathrm{CN}$ 들에게 시그널링 을 보낼 필요는 없지만 $\mathrm{LCoA}$ 가 변경되면 $\mathrm{MAP}$ 에게 시그널 링을 전송해야 한다. 따라서 $\mathrm{MAP}$ 안의 $\mathrm{MN}$ 의 움직임은 $\mathrm{HA}$ 나 $\mathrm{CN}$ 들이 알 수 없다. 그리고 $\mathrm{MN}$ 이 $\mathrm{MAP}$ 안의 도메인에 서 글로벌 로밍을 할 때에는 HMIPv6보다 MIPv6를 사용하 는 것이 낫다. $\mathrm{MN}$ 이 새로운 $\mathrm{MAP}$ 안의 도메인에 접근하여 새로운 $\mathrm{MAP}$ 에 등록하게 되면 새로운 위치의 $\mathrm{MN}$ 를 통제하 기 위해 $\mathrm{HA}$ 와 $\mathrm{CN}$ 들에게 시그널링을 전송해야 한다. HMIPv6의 프로토콜은 Fig. 6에서 확인 할 수 있고 $\mathrm{MN}$ 이 새로운 $\mathrm{MAP}$ 도메인에 $\mathrm{MIPv} 6$ 의 절차가 이미 이루어졌다고 가정한 HMIPv6의 메시지 흐름 순서는 아래 Fig. 7에서 확 인할 수 있다.

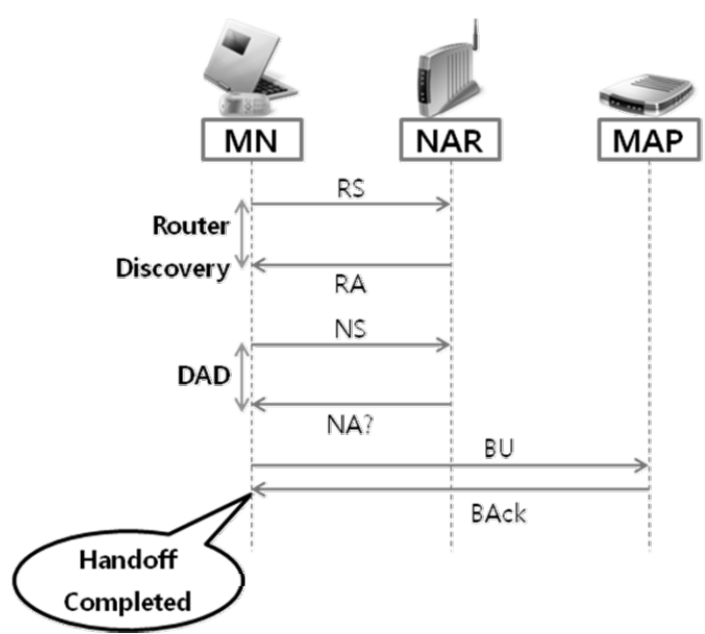

Fig. 7. Message flow diagram of the HMIPv6 protocol 


\subsection{F-HMIPV6}

F-HMIPv6(Fast Handover for HMIPv6)[14]는 핸드오버 시 FMIPv6와 마찬가지로 효율적인 네트워크 대역폭 사용을 허용하기 위해 HMIPv6와 FMIPv6의 조합으로 이루어진 프 로토콜이다. 또한 FMIPv6처럼 핸드오프 지연 및 패킷 손실 을 줄이는 것을 목표로 하고 있다. 그러기 위해 F-HMIPv6 는 FMIPv6처럼 $\mathrm{PAR}$ 와 $\mathrm{NAR}$ 사이에 터널링을 설치하는 것 이 아니라 MAP과 NAR사이에 양방향 터널을 생성한다. 해 당 프로토콜은 Fig. 8에서 확인 할 수 있다.

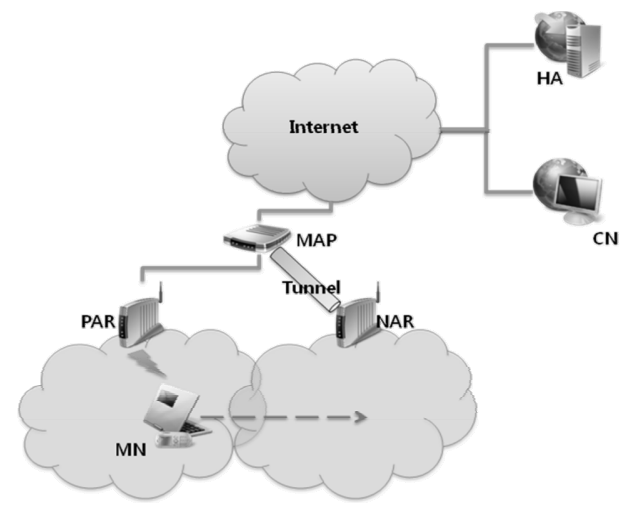

Fig. 8. F-HMIPv6 protocol

$\mathrm{MN}$ 와 MAP간의 메시지 교환이 이루어진 후 $\mathrm{HMIPv6}$ 와 같이 $\mathrm{MAP}$ 에게 $\mathrm{LBU}(\mathrm{Local}$ Binding Update)를 전송한다. $\mathrm{MAP}$ 이 MN로 부터 $\mathrm{NLCoA}(\mathrm{New} \mathrm{LCoA}$ )를 포함한 L시그널 링을 수신하면 $\mathrm{MAP}$ 은 $\mathrm{NAR}$ 에게 패킷 전송을 중지하고 생 성한 양방향 터널을 제거한다. LBU에 응답하기 위해 MAP 는 $\mathrm{MN}$ 에게 $\mathrm{LBAck}(\mathrm{Local} \mathrm{BAck})$ 를 전송하고 그 후의 절차 는 HMIPv6의 절차를 따른다. F-HMIPv6는 핸드오버가 지 원하지 않을 때를 대비하여 HMIPv6의 절차를 따를 것을 권장하고 있다[14]. 따라서 HMIPv6는 F-HMIPv6의 Reactive 모드에 해당한다. 이미 $\mathrm{MN}$ 이 $\mathrm{MAP}$ 의 도메인 상에 $\mathrm{PAR}$ 에서 $\mathrm{NAR}$ 로 이동한 상태이고 $\mathrm{MAP}$ 이 링크 계층 주소 와 각 $\mathrm{AR}$ 의 네트워크 Prefix에 대한 정보를 알고 있는 경우 F-HMIPv6에서 사용되는 메시지의 순서를 Fig. 9에서 확인 할 수 있다. 이 그림은 이미 $\mathrm{MN}$ 이 새로운 $\mathrm{MAP}$ 에 대해 $\mathrm{MIPv6}$ 절차와 HMIPv6의 등록 절차를 이미 완료했다는 가 정을 기반으로 한다.

\subsection{PMIPV6}

IPv6기반 네트워크에서는 MIPv6의 기능을 가지지 않은 $\mathrm{MN}$ 이 핸드오프를 시도하면 기존 네트워크의 연결을 종료 하고 새로운 연결을 새로 개설해야한다. 이를 방지하기 위 하여 MIIPv6의 기능이 없어도 기존에 설정되어 있는 연결 을 계속 유지하기 위하여 제안하는 프로토콜이 PMIPv6 (Proxy MIPv6)[19]이다. PMIPv6는 LMA(Local Mobility Anchor)와 MAG(Mobile Access Gateway) 그리고 AAA(Authentication, Authorization and Accounting) 서버 의 새로운 구성요소로 이루어져있다. 여기서 $\mathrm{MAG}$ 는 $\mathrm{MN}$ 을

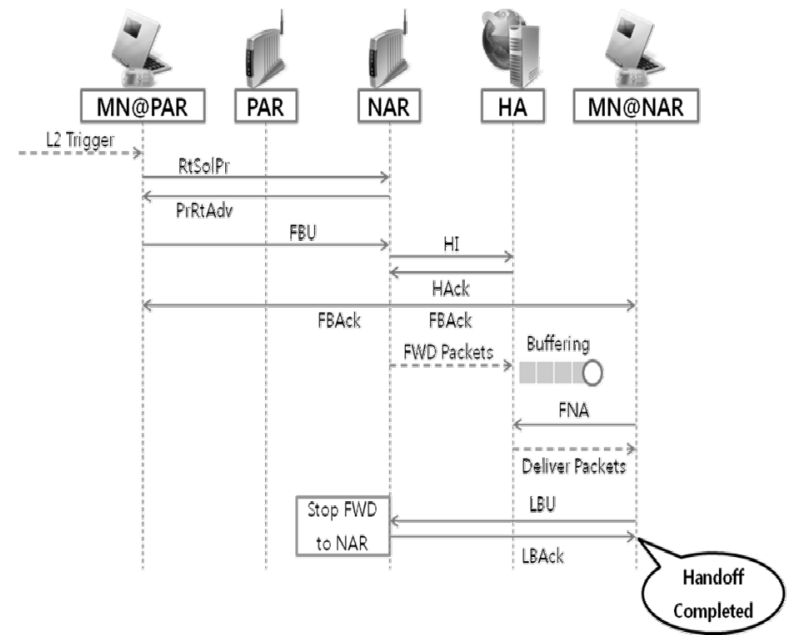

Fig. 9. Message flow diagram of the F-HMIPv6 protocol

대신하여 $\mathrm{MN}$ 의 이동성을 지원한다. $\mathrm{MN}$ 이 접속되어 있는 액세스 네트워크에서 기본 게이트웨이로 동작한다. 또한 PMIPv6 도메인 내의 $\mathrm{MN}$ 을 위한 일종의 $\mathrm{HA}$ 로 동작하는 것이 $\mathrm{LMA}$ 이다.

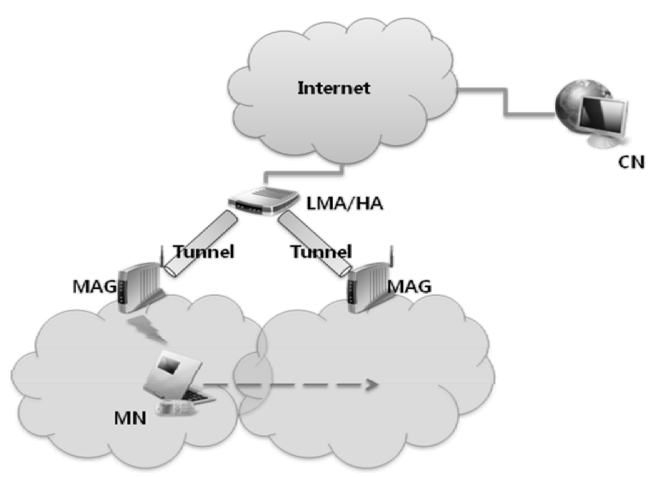

Fig. 10. PMIPv6 protocol

PMIPv6 프로토콜의 동작은 $\mathrm{MN}$ 이 처음 도메인에 접근하 여 $\mathrm{MAG}$ 가 접속되어 있는 액세스 링크에 접속하면 $\mathrm{MAG}$ 는 이를 감지하여 인증과정을 거쳐 $\mathrm{MN}$ 의 고유한 키 값을 이용 하여 $\mathrm{MN}$ 의 정보를 얻어낸다. $\mathrm{MN}$ 에 대한 정보에는 $\mathrm{MN}$ 의 $\mathrm{LMAA}(\mathrm{LMA}$ Address)와 주소 설정 방법 등과 같은 네트워 크 기반 이동성 지원 서비스를 제공하기 위한 파라미터들이 포함된다. $\mathrm{MAG}$ 는 $\mathrm{MN}$ 의 프로파일 정보를 이용하여 $\mathrm{LMA}$ 에 게 PBU(Proxy Binding Update) 메시지를 전송한다. PBU 메시지의 소스 IP 주소는 MAG의 IP 주소인 Proxy- CoA이 며 목적지 IP 주소는 LMAA로 설정된다. $\mathrm{PBU}$ 메시지를 수 신한 $\mathrm{LMA}$ 는 $\mathrm{PBU}$ 메시지 내에 있는 정보를 이용하여 $\mathrm{MAG}$ 와 터널을 설정한다. 그리고 $\mathrm{LMA}$ 는 터널 설정 및 바인딩 캐쉬 엔트리의 업데이트가 완료되었다는 것을 알리기 위하여 PBAck(Proxy Binding Acknowledgement) 메시지를 MAG 에게로 전송한다. $\mathrm{LMA}$ 로부터 PBAck 메시지를 수신한 $\mathrm{MAG}$ 는 $\mathrm{LMA}$ 와 터널을 설정하고 $\mathrm{MN}$ 이 IP 주소를 설정할 수 있도록 $\mathrm{RA}$ 메시지를 전송한다. 연결설정이 완료되면 
$\mathrm{MAG}$ 는 해당 $\mathrm{MN}$ 에서 오는 모든 트래픽을 $\mathrm{LMA}$ 와 연결된 터널을 이용하여 LMA에게 전송하게 되며, $\mathrm{LMA}$ 는 외부에서 오는 모든 트래픽을 해당 $\mathrm{MN}$ 을 관리하는 $\mathrm{MAG}$ 에게 전송하 게 된다. PMIPv6의 프로토콜은 Fig. 10에서 확인할 수 있고 메시지 흐름 순서는 아래 Fig. 11에서 확인할 수 있다.

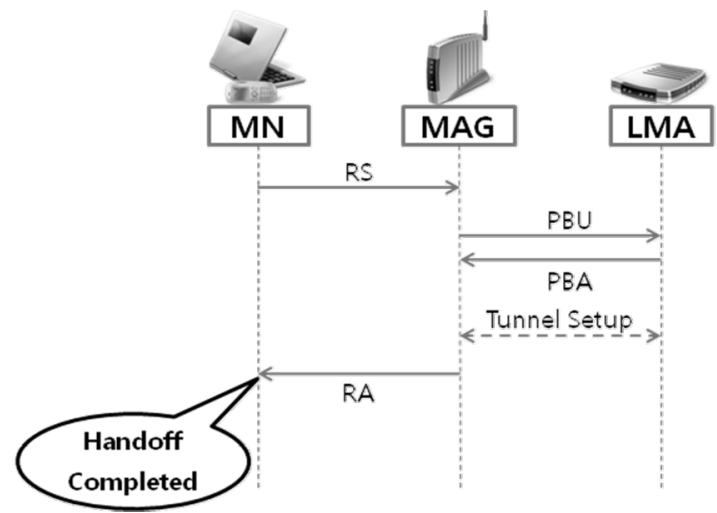

Fig. 11. Message flow diagram of the PMIPv6 protocol

\subsection{FPMIPV6}

FPMIPv6(Fast handovers for PMIPv6)[20] 프로토콜은 PMIPv6에 Fast Handover를 적용함으로써 핸드오프 지연시 간을 최소화하고 패킷 손실을 줄인 프로토콜이다.

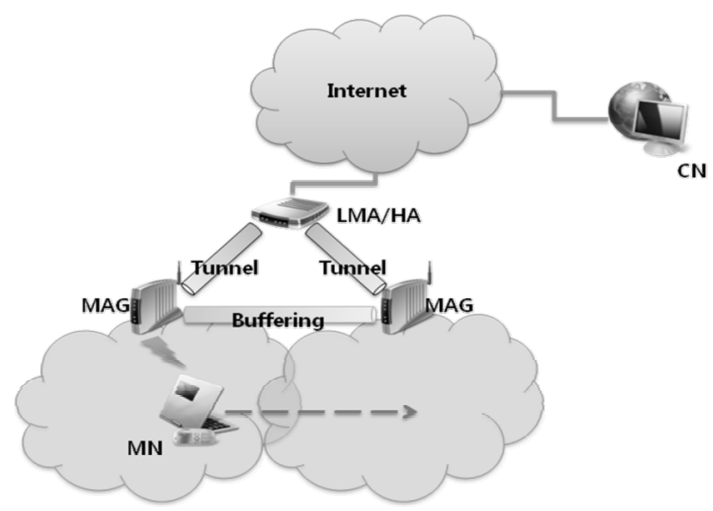

Fig. 12. FPMIPv6 protocol
PMIPv6는 핸드오버가 진행하는 동안 버퍼링을 사용하지 않기 때문에 핸드오프 절차와 별도로 인증 및 등록 단계를 수행해야만 했다. 그래서 FPMIPv6는 기존의 FMIPv6와 마 찬가지로 $\mathrm{MN}$ 이 $\mathrm{NMAG}(\mathrm{New} \mathrm{MAG})$ 로 접근할 때 PMAG(Previous MAG)와 NMAG 사이에 터널을 생성하여 $\mathrm{MN}$ 이 핸드오버 수행중에 패킷을 터널링 함으로써 패킷손 실을 줄이고자 제안되었다. $\mathrm{MN}$ 이 핸드오버를 수행하면 $\mathrm{PMAG}$ 는 NMAG로 $\mathrm{HI}$ 메시지를 전송하고 NMAG는 $\mathrm{HI}$ 에 대한 결과로 Hack 메시지를 PMAG로 전송하고 PMAG와 $\mathrm{NMAG}$ 사이에 터널이 생성된다. 새로운 도메인으로 이동 한 $\mathrm{MN}$ 이 NMAG와 새로운 연결을 생성하면 NMAG는 $\mathrm{LMA}$ 로 $\mathrm{PBU}$ 메시지를 전송하고 그에 대한 결과로 $\mathrm{PBAck}$ 메시지를 수신한다. FPMIPv6의 프로토콜은 Fig. 12에서 확 인할 수 있고 메시지 흐름 순서는 아래 Fig. 13에서 확인할 수 있다.

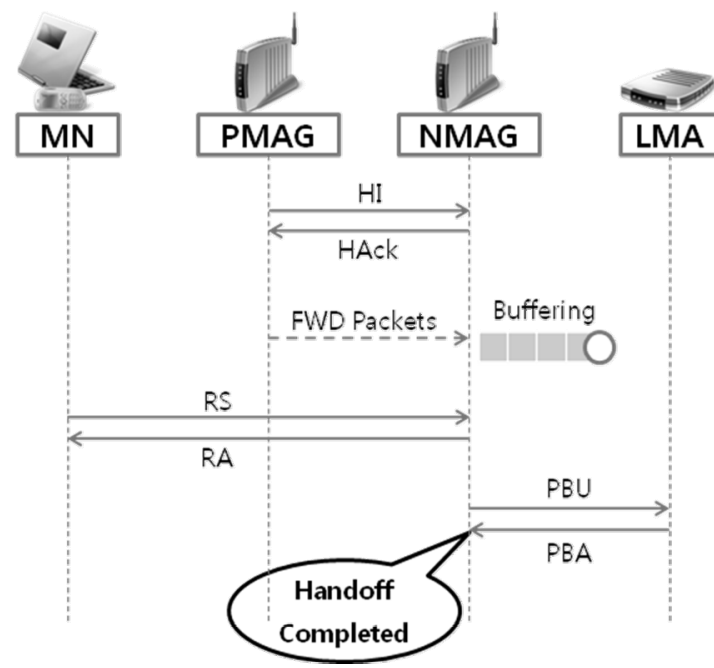

Fig. 13. Message flow diagram of the FPMIPv6 protocol

Table 1은 논문에서 분석하고자 하는 무선 네트워크 상 에서의 이동성관리 프로토콜에 대해 간단하게 분석해놓은 내용이다.

Table 1. Comparison of IP-based wireless network mobility management protocols

\begin{tabular}{|c|c|c|c|c|c|c|}
\hline 특성 & MIPv6 & FMIPv6 & HMIPv6 & F-HMIPv6 & PMIPv6 & FPMIPv6 \\
\hline 이동성 관리 범위 & Global & Global/Local & Global & Global/Local & Global & Global/Local \\
\hline $\begin{array}{c}\text { 지원 가능한 } \\
\text { IP 버전 }\end{array}$ & IPv6 & IPv6 & IPv6 & IPv6 & $\mathrm{IPv} 4 / \mathrm{IPv} 6$ & IPv4/IPv6 \\
\hline 라우팅 최적화 지원 & 지원 & - & 지원 & 지원 & 지원안함 & 지원 \\
\hline 핸드오버 종류 & Reactive & $\begin{array}{l}\text { Predictive/ } \\
\text { Reactive }\end{array}$ & Reactive & $\begin{array}{l}\text { Predictive/ } \\
\text { Reactive }\end{array}$ & Reactive & $\begin{array}{l}\text { Predictive/ } \\
\text { Reactive }\end{array}$ \\
\hline QoS 지원 & 부분 지원 & 부분 지원 & 지원 & 지원 & 지원 & 지원 \\
\hline 이동성 관리 분류 & \multicolumn{4}{|c|}{ 호스트 기반 프로토콜 } & \multicolumn{2}{|c|}{ 네트워크 기반 프로토콜 } \\
\hline $\mathrm{MN}$ 터널링 오버헤드 & \multicolumn{4}{|c|}{ 발생(높음) } & \multicolumn{2}{|c|}{ 발생하지 않음 } \\
\hline $\mathrm{MN}$ 정보 수정 & \multicolumn{4}{|c|}{ 필요함 } & \multicolumn{2}{|c|}{ 필요하지 않음 } \\
\hline 다중유도 (Multi-Homing) 여부 & \multicolumn{4}{|c|}{ 지원하지 않음 } & \multicolumn{2}{|c|}{ 지원 } \\
\hline L4 지원여부 & \multicolumn{4}{|c|}{ 지원 불가 } & \multicolumn{2}{|c|}{ 지원 가능 } \\
\hline
\end{tabular}




\section{3. 이동성지원 프로토콜의 성능분석 모델링}

IPv6 기반 무선 네트워크의 QoS(Quality of Service) 보 장은 패킷 손실, 핸드오프 지연에 의해 정의될 수 있다. 이 러한 통계 분석 항목들은 IPv6기반의 모바일 환경에서의 이 동성관리 프로토콜의 성능을 평가하는데 매우 유용하다. 3 장에서는 이동성 프로토콜의 성능을 평가하기 위한 분석 프 레임워크를 제안하고자 한다. 본 논문에 사용되는 매개변수 는 Table 2에서 확인할 수 있다.

변수 $x_{T}$ 는 $\mathrm{L} 2$ 트리거 생성과 핸드오버 대기중인 $\mathrm{L} 2$ 다운 링크 사이의 시간을 정의한 것이고, $\sigma>1$ 일때 $f_{T}(u, \sigma)$ 는 성공적으로 시그널링을 완료 했을 시의 확률 밀도 함수를 나 타낸 것이다. 확률변수 $P_{s}$ 는 핸드오버가 성공한 시그널을 확 인했을 때의 변수 $t_{T}$ 값을 통해 다음과 같이 나타낼 수 있다.

Table 2. Parameters

\begin{tabular}{|c|c|}
\hline 매개변수 & 설명 \\
\hline$\lambda_{s}$ & 포아송 분포에 따른 세션 도착률 \\
\hline$\mu_{c}$ & 네트워크 경계에서 내부(MAG/AR)로 돌아올 확률 \\
\hline$\mu_{d}$ & 네트워크 경계에서 외부로 액세스 할 확률 \\
\hline$\mu_{l}$ & 네트워크 경계에 남아있을 확률 \\
\hline$t_{c}$ & 네트워크 경계에서 내부의 체류시간 확률변수 \\
\hline$t_{d}$ & 네트워크 경계에서 외부의 체류시간 확률변수 \\
\hline$t_{T}$ & 링크 변경부터 L2트리거 까지의 시간 \\
\hline$f_{c}$ & $t_{c}$ 의 PDF(Probability Density Function) \\
\hline$f_{d}$ & $t_{d}$ 의 $\mathrm{PDF}$ \\
\hline$t_{s}$ & $f_{c}$ 와 $f_{d}$ 간의 상호 세션 시간 \\
\hline$N_{c}$ & 네트워크 경계에서 내부로 돌아오는 개수 \\
\hline$N_{d}$ & 네트워크 경계에서 외부로 액세스하는 개수 \\
\hline$N_{C N}$ & $\mathrm{MN}$ 에 대한 $\mathrm{CN}$ 의 바인딩 캐시 엔트리가 가능한 수 \\
\hline$C^{g}$ & $\mathrm{HA} / \mathrm{CN}$ 에 대한 글로벌 시그널링 비용 \\
\hline$C^{l}$ & LMA/MAP에 대한 로컬 시그널링 비용 \\
\hline$M$ & AN/LMA/MAP 도메인의 개수 \\
\hline$P_{s}$ & 핸드오프 예측율 \\
\hline$d_{X, Y}$ & $\mathrm{X}$ 와 Y사이의 평균 Hop수 \\
\hline$C_{X, Y}$ & $\mathrm{X}$ 와 $\mathrm{Y}$ 사이의 컨트롤 패킷 전송 비용 \\
\hline$P C_{X}$ & $\mathrm{X}$ 의 컨트롤 패킷 처리 비용 \\
\hline$C_{h c}$ & $\mathrm{HA}$ 와 $\mathrm{CN}$ 의 시그널링 비용 \\
\hline$C_{r r}$ & $\mathrm{RR}$ 프로시져의 비용 \\
\hline
\end{tabular}

$$
P_{s}=P_{r}\left(x_{T}>t_{T}\right)=\int_{t_{T}}^{\infty} f_{T}(u, \sigma) d u
$$

일반적으로 $f_{T}(u, \sigma)$ 의 정확한 형식을 알 수 없을때에는 확률변수 $P_{s}$ 를 구하기 어렵다. 단순하게 구하기 위해 변수 $x_{T}$ 는 기하 급수적으로 분산되어 있다고 가정하자.

\section{1 사용자 이동성 모델 및 트래픽 모델}

사용자의 이동성 모델과 트래픽 모델은 효율적인 시스템 설계 및 성능 평가를 위해 중요하다. 본 논문에서는 세션과 패킷, 두 가지 수준으로 구성된 트래픽 모델을 고려하였다. 일반적으로 $\mathrm{MN}$ 의 이동성은 네트워크 셀 거주 시간과 다양 한 형태의 임의의 변수에 대응하기 위해 모델링한다[15]. 차 세대 무선 네트워크에서 내부 호출을 하거나 내부 도착 시 간이 기하급수적으로 분산 될 때 포아송 프로세스를 수행하 지만 외부 세션 도착시간은 기하 급수적으로 분산되지 않을 수가 있다[15]. 트래픽 모델은 하이퍼 Erlang, Gamma, Pareto 같은 무선 네트워크의 다양한 시간 변수를 사용하여 제안한다. 그러나 성능 평가를 위한 지수 모델은 [15]에서 사용한 비용 분석 지수 모델을 따른다. 사실 지수 모델은 복잡성과 정확성 사이의 상관관계 허용을 제공한다.

$\mu_{c}$ 는 네트워크 경계선에서 내부 (MAG)로 다시 돌아올 확률을 나타내고, $\mu_{d}$ 는 네트워크 경계선에서 외부의 네트 워크에 액세스(AN)하거나 LMA에 속한 도메인에 접근할 확률을 나타낸다. 또한 $\mu_{l}$ 은 여전히 경계선에 남아있을 확 률을 나타내는 변수다. $\mathrm{MN}$ 이 $\mathrm{AN}$ 이나 $\mathrm{LMA}$ 도메인에 경계 를 지나갈 때 더불어 $\mathrm{MAG}$ 의 경계도 지나가게 된다. [16]에 따르면 $\mathrm{AN} / \mathrm{LMA}$ 의 커버리지 영역을 $M$ 으로, 서브넷의 크 기를 $a M A G$ 로 정의하면 경계를 지나가는 비율을 다음과 같이 얻을 수 있다.

$$
\mu_{d}=\frac{\mu_{c}}{\sqrt{M}} \text { and } \mu_{l}=\mu_{c}-\mu_{d}=\mu_{c} \frac{\sqrt{M}-1}{\sqrt{M}}
$$

$\mu_{c}=2 \frac{v}{\sqrt{\pi a M A G}}$ 에서 $v$ 는 $\mathrm{MN}$ 이 이동하는 평균 속도이 고, $a M A G=\pi R^{2}$ 일때 $R$ 은 액세스하는 라우터의 반경이다. 호출 요청 중인 무선 셀룰러 네트워크에 대한 비용을 분 석하는 것은 네트워크 경계의 확률 분포를 모델링 하는데 있어서 매우 중요한 역할을 한다. Fig. 13은 모바일 사용자 가 내부 세션에 머무를 때 $M A G_{i}$ 와 $M A G_{j}$ 의 경계에서 이 동하는 타이밍을 그림으로 표현한 것이다. $T_{r s}$ 는 남아 있는 서브넷 거주 시간을 나타낸다. 


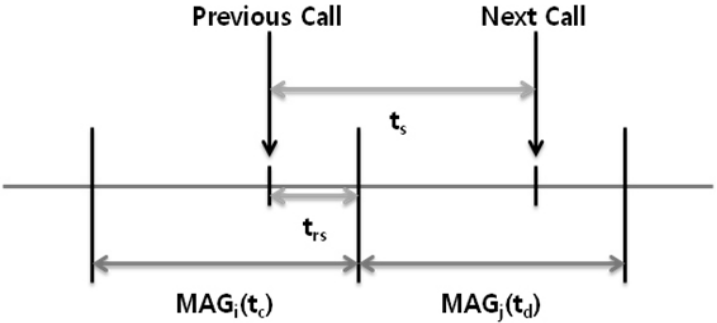

Fig. 14. Timing diagram for subnet boundary crossing

Table 2와 Fig. 14에 따라 서브넷으로의 이동 확률은 $P_{c}$ 로, $\mathrm{AN} / \mathrm{LMA}$ 도메인으로의 이동 확률은 $P_{d}$ 로 정의했을때 $P_{c}$ 와 $P_{d}$ 는 다음과 같이 구할 수 있다.

$$
\begin{aligned}
& P_{c}=\operatorname{Pr}\left(t_{s}>t_{c}\right)=\int_{0}^{\infty} \operatorname{Pr}\left(t_{s}>u\right) f_{c}(u) d u \\
& P_{d}=\operatorname{Pr}\left(t_{s}>t_{d}\right)=\int_{0}^{\infty} \operatorname{Pr}\left(t_{s}>u\right) f_{d}(u) d u
\end{aligned}
$$

$\mathrm{MN}$ 이 네트워크 경계에서 되돌아올 확률을 $k$ 로 정의하 고 네트워크 경계에서 다른 네트워크로 이동할 확률을 $m$ 으로 정의 했을때 $N_{c}$ 와 $N_{d}$ 의 확률함수로 정의하면 다음과 같이 정의한다.

$$
\begin{aligned}
& \operatorname{Pr}\left(N_{c}=k\right)=P_{c}^{k}\left(1-P_{c}\right) \\
& \operatorname{Pr}\left(N_{d}=m\right)=P_{c}^{m}\left(1-P_{d}\right)
\end{aligned}
$$

그리고 두 네트워크 경계에서 세션 시간 동안 이전 서브 넷의 위치 시그널링을 하는 수의 평균은 $E\left(N_{c}\right)$ 로 $\mathrm{AN} / \mathrm{LMA}$ 도메인에 위치 시그널링을 하는 수의 평균을 $E\left(N_{d}\right)$ 로 정의 하면 다음의 식을 얻어낼 수 있다.

$$
\begin{aligned}
& E\left(N_{c}\right)=\sum_{k=0}^{\infty} k \operatorname{Pr}\left(N_{c}=k\right)=\sum_{k=0}^{\infty} k \mathrm{P}_{c}^{k}\left(1-P_{c}\right) \\
& E\left(N_{d}\right)=\sum_{k=0}^{\infty} m \operatorname{Pr}\left(N_{d}=m\right)=\sum_{k=0}^{\infty} m \mathrm{P}_{c}^{m}\left(1-P_{d}\right)
\end{aligned}
$$

시그널링 비용을 단순하고 쉽게 유도하기 위해 기하급수 적으로 늘어난다고 가정하고 세션 도착률을 포아송 분포에 따라 $\lambda_{s}$ 로, 서브넷에서 이루어지는 체류시간의 지수분포를 $\mu_{c}$ 로, $\mathrm{AN} / \mathrm{LMA}$ 에서 이루어지는 체류시간의 지수분포를 $\mu_{d}$ 로 정의하면 세션 시간 동안 이동확률 및 위치 업데이트 평균개수는 다음과 같이 얻을 수 있다.

$$
\begin{aligned}
& P_{c}=\frac{\mu_{c}}{\mu_{c}+\lambda_{s}} \text { and } P_{d}=\frac{\mu_{d}}{\mu_{d}+\lambda_{s}} \\
& E\left(N_{c}\right)=\frac{\mu_{c}}{\lambda_{s}} \text { and } E\left(N_{d}\right)=\frac{\mu_{d}}{\lambda_{s}}
\end{aligned}
$$

마찬가지로 경계 내에서 어느 쪽으로도 이동하지 않는 $\mathrm{MN}$ 의 평균 숫자는 $E\left(N_{l}\right)$ 로 나타낼 수 있다.

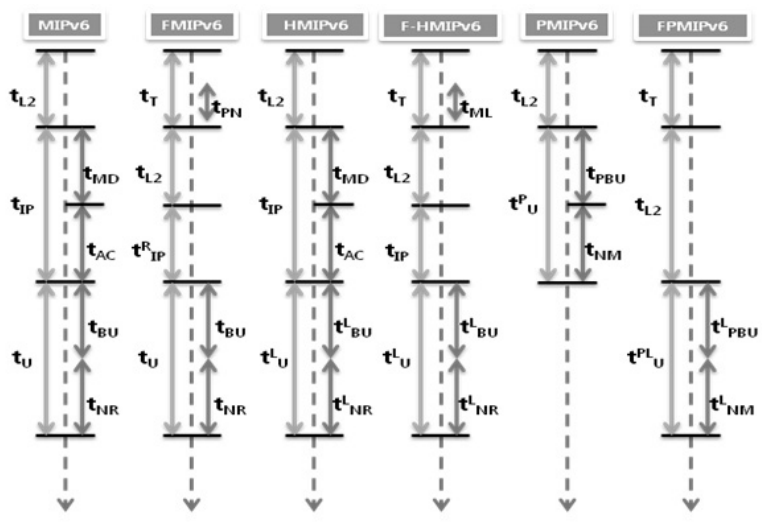

Fig. 15. Handoff Timeline of mobility management protocols

\section{2 총 시그널링 비용}

무선 네트워크의 성능 분석은 이동성관리 프로토콜에 의 해 유도된 총 시그널링 비용을 고려해야 한다. 총 시그널링 비용은 $\mathrm{MN}$ 의 시그널링 비용과 패킷전달 비용의 합으로 정 의하는데 수식은 다음과 같이 정의한다.

$$
C_{T}=C_{B U}+C_{P D}
$$

인증 및 L2 핸드오프에 필요한 비용은 모든 프로토콜에 서 같기 때문에 분석에서는 생략한다.

\section{3 시그널링 비용}

시그널링 비용은 움직임의 종류와 프로토콜에 따라 두 가 지의 종류로 분류할 수 있는데 MIPv6와 FMIPv6의 경우 $\mathrm{MN}$ 의 움직임에 관계없이 $\mathrm{NCoA}$ 를 획득하고 $\mathrm{HA}$ 와 $\mathrm{CN}$ 들에 등록할 때마다 글로벌 바인딩 업데이트가 수행된다. 반면 HMIPv6 같은 경우 MAP 도메인 내에서 IP주소가 변경될 때에는 로컬 바인딩 업데이트가 수행되지만 MAP 도메인 밖으로 이동할 때는 글로벌 바인딩 업데이트가 수행된다. 그러므로 IPv6 기반 이동성관리 프로토콜에 대한 평균 시그 널링 비용의 수식은 다음과 같이 정의한다.

$$
C_{B U}=E\left(N_{l}\right) C^{l}+E\left(N_{d}\right) C^{g}
$$

시그널링 비용 계산 시 필요한 성능 요소는 $\mathrm{SMR}$ (Session to Mobility Ratio)이라고 하는 요소인데 수식에 적 용하면 다음과 같다. 


$$
C_{B U}=\frac{1}{\lambda_{s}}\left(\mu_{d} C^{g}+\mu_{l} C^{l}\right)=\frac{1}{S M R \sqrt{M}}\left[C^{g}+(\sqrt{M}-1) C^{l}\right)
$$

IP 네트워크에서 패킷 전송 비용은 시작 노드와 대상 노 드 사이에 hop 수의 비례하고, 유선 네트워크 보다 무선 네 트워크의 전송 비용이 일반적으로 크다[7]. 따라서 두 노드 사이에 패킷 전송 비용은 $C_{X, Y}=\tau d_{X, Y}$ 로 정의하되 $\mathrm{MN}$ 과 라우터의 패킷 전송 비용은 $C_{M N, A R}=\tau \kappa$ 로 정의한다. $\tau$ 는 유선 네트워크 상의 가중치, $\kappa$ 는 무선 네트워크 상의 전송 비용 가중치다.

$\mathrm{MIPv6}$ 와 HMIPv6의 로컬 시그널링 비용과 글로벌 시그 널링 비용은 수식은 다음과 같이 정의한다.

$$
\begin{gathered}
C_{M I P v 6}^{g}=C_{M I P \vee 6}^{l}=4 C_{M N, A R}+2 P C_{A R}+C_{h c} \\
C_{H M I P \vee 6}^{l}=2\left(2 C_{M N, A R}+P C_{A R}+C_{M N, M A P}\right)+P C_{M A P} \\
C_{h c}=2(10) \\
\left.C_{r r}=2\left(C_{M N, H A}+N_{C N} C_{M N, C N}\right)+P C_{H A}+N_{C N} P C_{C N}+C_{r r} C_{H A, C N}+N_{C N} C_{M N, C N}+P C_{H A}+N_{C N} P C_{C N}\right) \\
C_{h c} \text { 는 핸드오프 완료에 필요한 시그널링 비용을 나타낸 }
\end{gathered}
$$
것이며 $C_{r r}$ 은 $\mathrm{RR}$ 프로시져 수행 시의 시그널링 비용을 나타 낸다.

$\mathrm{FMIPv6}$ 에서는 $\mathrm{MN}$ 의 이동에 대해 미리 예측하거나 빠르 게 응답하는 프로토콜이므로 핸드오버의 확률에 따라 시그 널링 비용이 달라지는데 수식은 다음과 같이 정의한다.

$$
\begin{aligned}
C_{F M I P \vee 6}^{l} & =P_{S} S_{S}+\left(1-P_{S}\right)\left(S_{f}+S_{r}\right)+C_{h c} \\
S_{s} & =4 C_{M N, P A R}+3 C_{P A R, N A R}+2 C_{M N, N A R}+5 P C_{A R} \\
S_{f} & =3 C_{M N, P A R}+2 C_{P A R, N A R}+3 P C_{A R} \\
S_{r} & =2 C_{M N, P A R}+2 C_{P A R, N A R}+2 C_{M N, N A R}+3 P C_{A R}
\end{aligned}
$$

$S_{s}$ 는 호스트기반 이동성지원 프로토콜의 핸드오버 성공 시의 시그널링 비용을 나타내며, $S_{f}$ 는 호스트기반 이동성지 원 프로토콜의 핸드오버 실패시의 시그널링 비용을 나타내 며, $S_{r}$ 은 Reactive 모드로 핸드오프를 완료했을 때의 시그 널링 비용을 나타낸다.

F-HMIPv6는 FMIPv6에 대한 유사한 추론과 가정에서 시그널링 비용의 계산을 허용하는데 F-HMIPv6의 로컬 시 그널링 비용은 다음과 같이 정의한다.

$$
C_{F H M I P \vee}^{l}=P_{S} S_{s}^{l}+\left(1-P_{S}\right) S_{f}^{l}+S_{h}^{l}
$$

$$
\begin{aligned}
& S_{s}^{l}=4 C_{M N, M A P}+3 C_{M A P, N A R}+2 C_{M N, N A R}+3 P C_{M A P}+2 P C_{A R} \\
& S_{f}^{l}=3 C_{M N, M A P}+2\left(C_{M A P, N A R}+P C_{M A P}\right)+P C_{A R} \\
& S_{h}^{l}=P_{S}\left[2\left(C_{M N, N A R}+C_{N A R, M A P}\right)+P C_{N A R}+P C_{M A P}\right]+\left(1-P_{S}\right) C_{H M I P v 6}^{l} \\
& S_{s}^{l} \text { 는 } \mathrm{F}-\mathrm{HMIPv} 6 \text { 에서의 핸드오프 성공시의 시그널링 비 }
\end{aligned}
$$
용을 나타내며, $S_{f}^{l}$ 는 $\mathrm{F}-\mathrm{HMIPv} 6$ 에서의 핸드오프 실패시의 시그널링 비용을 나타내며, $S_{h}^{l}$ 는 F-HMIPv6에서의 핸드오 프 완료시의 시그널링 비용을 나타낸다.

$\mathrm{HMIPv6}$ 와 $\mathrm{FMIPv6}$ 는 $\mathrm{AN} / \mathrm{MAP}$ 도메인 내의 움직임에 대해서는 MIPv6보다 성능을 향상 시킬 수 있지만 $\mathrm{AN} /$ $\mathrm{MAP}$ 도메인간의 움직임에 대해서는 MIPv6의 성능이 같다.

PMIPv6의 경우 메시징 프로세스에 따라 내부의 로컬 바 인딩 비용과 외부의 글로벌 바인딩 비용으로 나눌 수 있고 $\mathrm{PMIPv6}$ 의 경우 MAG와 LMA사이의 $\mathrm{PBU}$ 와 $\mathrm{PBA}$ 메시지를 통해 바인딩을 수행하므로 수식은 다음과 같이 정의 할 수 있다.

$$
\begin{aligned}
& C_{P M I P v 6}^{g}=C_{P M I P v 6}^{l}+2 C_{L M A, L M A}+2 P C_{L M A} \\
& C_{P M I P v 6}^{l}=2 C_{M N, M A G}+2 C_{M A G, L M A}+2 P C_{M A G}+P C_{L M A}
\end{aligned}
$$

$\mathrm{FPMIPv6}$ 의 경우 $\mathrm{FMIPv6}$ 와 같이 $\mathrm{MN}$ 의 이동에 따른 핸 드오버의 확률에 따라 비용이 달라지고 수식은 다음과 같 이 정의한다.

$$
\begin{aligned}
& C_{F P M I P v 6}^{l}=P_{S} S_{s}^{p}+\left(1-P_{S}\right) S_{f}^{p} \\
& S_{s}^{p}=2 C_{M N, M A G}+2 C_{P M A G, N M A G}+2 C_{M A G, L M A}+3 P C_{M A G}+P C_{L M A} \\
& S_{f}^{p}=2 C_{M N, M A G}+2 C_{P M A G, N M A G}+2 C_{M A G, L M A}+5 P C_{M A G}+P C_{L M A} \\
& S_{s}^{p} \text { 는 네트워크기반 이동성지원 프로토콜에서 핸드오버 }
\end{aligned}
$$
성공시의 비용을 나타낸 매개변수이며, $S_{f}^{p}$ 는 네트워크기반 이동성지원 프로토콜에서 핸드오버 실패시의 비용을 나타낸 매개변수이다.

\section{4 패킷 전송 비용}

[17]에 따르면 핸드오프 지연율은 기본적으로 세 가지의 구성요소로 나눌 수 있는데 첫 번째는, 링크 스위칭(link switching)이나 L2계층의 핸드오프 지연 $\left(t_{L 2}\right)$ 이고 두번째 는, IP 연결 지연 $\left(t_{I P}\right)$ 세번째는, 위치 정보 업데이트 지연 $\left(t_{U}\right)$ 이다. 그 외에도 각 프로토콜에 따라 패킷 수신 지연 $\left(t_{P}\right)$, 이동 검출 지연 $\left(t_{M D}\right), \mathrm{DAD}$ 프로시져 실행 시 주소 구 성 지연 $\left(t_{A C}\right)$, 시그널링 지연 $\left(t_{B M}\right)$, 새 $\mathrm{IP}$ 주소로 바인드 업 
데이트 후 첫 패킷 수신 완료까지의 지연 $\left(t_{N R}\right)$ 등이 발생할 수 있다.

패킷 전송 비용은 패킷의 터널링 비용 $\left(C_{t u n}\right)$ 및 패킷 손 실 비용 $\left(C_{\text {loss }}\right)$ 의 조합으로 정의하며 수식은 다음과 같이 정의한다.

$$
C_{P D}=\alpha C_{t u n}+\beta C_{\text {loss }}
$$

컨트롤 패킷과 데이터 패킷의 평균 크기는 각각 $s_{c}$ 와 $s_{d}$ 로 정의 하고 데이터 패킷 전송 비용은 $\left(\eta, \eta=s_{d} / s_{c}\right)$ 로 정의한다. 또한 시간당 패킷 전송률은 $\lambda_{p}$ 로 정의한다. 터널 링 비용이 없는 MIPv6 패킷 전송 비용 수식은 다음과 같이 정의한다.

$$
\begin{gathered}
C_{\text {loss }}^{M I P v 6}=\lambda_{p} C_{c m}^{f, 1}\left(t_{L 2}+t_{I P}+t_{U}\right) \\
C_{c m}^{f, 1}=\eta\left(C_{C N, P A R}+C_{P A R, M N}\right)
\end{gathered}
$$

$C_{c m}^{f, 1}$ 은 핸드오프 실패 시 $\mathrm{CN}$ 에서 $\mathrm{PAR}$ 를 통해 $\mathrm{MN}$ 까지 가는 데이터 패킷 전송 비용이다. $t_{U}=t_{B U}+t_{N R}$, $t_{B U}=t_{H A}+t_{R R}+t_{C N}$ 이며 $t_{H A}$ 는 $\mathrm{HA}$ 에서의 $\mathrm{BU}$ 프로시져 수 행 시간, $t_{R R}$ 는 $\mathrm{RR}$ 프로시져 수행 시간, $t_{C N}$ 는 $\mathrm{CN}$ 들의 $\mathrm{BU}$ 프로시져 수행 시간을 나타낸다.

$\mathrm{HMIPv6}$ 의 경우도 터널링 비용이 없기 때문에 다음과 같 이 패킷 전송 비용을 정의할 수 있다.

$$
\begin{aligned}
& C_{\text {loss }}^{\text {HMIPv6 }}=\lambda_{p} C_{c m}^{f, 2}\left(t_{L 2}+t_{I P}+t_{U}^{L}\right) \\
& C_{c m}^{f, 2}=\eta\left(C_{C N, M A P}+C_{M A P, P A R}+C_{P A R, M N}+P C_{M A P}\right)
\end{aligned}
$$

핸드오프 실패 시 데이터 패킷 전송 비용은 $C_{c m}^{f, 2}$ 이며, $t_{U}^{L}$ 는 내부 $\mathrm{AN} / \mathrm{MAP}$ 에서의 로밍을 위한 위치 업데이트 지 연 시간을 나타내고 $t_{U}^{L}=t_{B U}^{L}+t_{N R}^{L}$ 이다.

FMIPv6 Predictive 모드는 패킷 손실을 피하기 위해 $\mathrm{PAR}$ 와 NAR사이에 버퍼링을 위한 터널을 생성하고 터널을 통해 모든 패킷을 전송하며 터널링 패킷 전송 비용은 다음 과 같이 정의한다.

$$
\begin{aligned}
C_{\text {tun }}^{F M I P v 6, p} & =\lambda_{p} C_{c m}^{s, 1}\left(t_{L 2}+t_{I P}^{P}+t_{U}\right) \\
C_{c m}^{s, 1} & =\eta\left(C_{C N, P A R}+C_{P A R, N A R}+C_{N A R, M N}\right) \\
C_{c m}^{s, 2} & =\eta\left(C_{C N, M A P}+C_{M A P, N A R}+C_{N A R, M N}+P C_{M A P}\right)
\end{aligned}
$$

$C_{c m}^{s, 1}$ 은 $\mathrm{PAR}$ 와 $\mathrm{NAR}$ 사이의 터널을 통한 $\mathrm{CN}$ 에서 $\mathrm{MN}$ 의 데이터 전송 비용으로 정의하고, $t_{I P}^{P}$ 는 Predictive 모드의 IP 접속 지연 시간을 나타낸다. FMIPv6 Predictive 모드 패킷 손실 비용은 다음과 같이 정의한다.

$$
C_{\text {loss }}^{F M I P v 6, p}=\lambda_{p} C_{c m}^{f, 1} \max \left(t_{P N}-t_{T}, 0\right)
$$

$t_{P N}$ 은 $\mathrm{PAR}$ 와 NAR사이에 터널 생성 시간인데 핸드오프 완료 패킷 전송이 성공적으로 전송되는 시간보다 터널 생성 이 늦었을 경우와 이미 생성이 완료되었다고 해도 핸드오프 완료 패킷 전송이 성공적으로 전송되었을 수도 있으므로 $\max \left(t_{P N}-t_{T}, 0\right)$ 값을 사용하는 것이다. 반면 Reactive 모드 에서는 NAR 공간의 잘못된 위치 예측이나 FBAck 메시지 가 이전 링크의 정보를 수신하지 못한 경우에 패킷이 손실 될 수 있기 때문에 Predictive 모드의 패킷 손실 비용은 다 음과 같이 정의한다.

$$
C_{\text {loss }}^{F M I P v 6, r}=\lambda_{p} C_{c m}^{f, 1}\left(t_{L 2}+t_{I P}^{R}+t_{U}\right)
$$

그래서 $\mathrm{FMIPv6}$ 의 평균 패킷 전송 비용은 다음과 같다.

$$
C_{P D}^{F M I P v 6}=P_{s} C_{P D}^{F M I P v 6, p}+\left(1-P_{s}\right) C_{P D}^{F M I P v 6, r}
$$

$\mathrm{F}-\mathrm{HMIPv} 6$ 의 패킷 전송 비용은 FMIPv6의 수식에서 $t_{U}$ 는 $t_{U}^{L}, t_{P N}$ 은 $t_{M L}, t_{I P}^{R}$ 는 $t_{I P}, C_{c m}^{s, 1}$ 는 $C_{c m}^{s, 2}, C_{c m}^{f, 1}$ 는 $C_{c m}^{f, 2}$ 로 치환하여 사용한다. $C_{c m}^{s, 2}$ 는 $\mathrm{MAP}$ 과 $\mathrm{NAR}$ 사이의 터널을 통 한 $\mathrm{CN}$ 과 $\mathrm{MN}$ 사이의 데이터 패킷 전송 비용이다. $t_{M L}$ 은 $\mathrm{MAR}$ 과 $\mathrm{NAR}$ 사이의 터널 생성 시간이다.

PMIPv6는 MIPv6와 유사하지만 MN에 대한 프로시져 수 행의 시간을 줄일 수 있고 터널링 비용은 없기 때문에 다음 과 같이 정의한다.

$$
\begin{aligned}
& C_{\text {loss }}^{P M I P v 6}=\lambda_{p} C_{c m}^{f, 3} t_{L 2} \\
& C_{c m}^{f, 3}=\eta\left(C_{C N, L M A}+C_{L M A, M A G}+C_{M A G, M N}+P C_{L M A}\right)
\end{aligned}
$$

$C_{c m}^{f, 3}$ 는 핸드오프 실패 시 $\mathrm{CN}$ 으로부터 $\mathrm{MN}$ 까지의 패킷전 송 비용을 나타낸다.

$\mathrm{FPMIPv6}$ 는 패킷 손실을 피하기 위해 $\mathrm{pMAG}$ 와 $\mathrm{nMAG}$ 사 이에 버퍼링을 위한 터널을 생성하고 터널을 통해 모든 패 킷을 전송하며 터널링 패킷 전송 비용은 다음과 같이 정의 한다. 
$C_{\text {tun }}^{F P M I P v 6}=\lambda_{p} C_{c m}^{s, 3} t_{L 2}$

$C_{c m}^{s, 3}=\eta\left(C_{C N, L M A}+C_{L M A, p M A G}+C_{p M A G, n M A G}+C_{n M A G, M N}+P C_{L M A}+2 P C_{M A G}\right)$

$C_{c m}^{s, 3}$ 는 $\mathrm{pMAG}$ 과 $\mathrm{nMAG}$ 사이의 터널을 통한 $\mathrm{CN}$ 과 $\mathrm{MN}$ 사 이의 데이터 패킷 전송 비용을 정의한 것이다.

3.5 필요한 버퍼 공간

핸드오버 시 필요한 버퍼 공간도 성능 분석에 필요한 요 소로 정의하고자 한다.

FMIPv6의 경우 필요한 버퍼 공간은 핸드오버를 수행하 는 $\mathrm{MN}$ 의 개수와 패킷 도착률, 핸드오프 지연시간에 비례하 며 수식은 다음과 같이 정의한다.

$$
B S_{F M I P v 6}^{l}=\lambda_{p}\left[P_{s}\left(t_{L 2}+t_{I P}^{P}+t_{U}\right)+\left(1-P_{s}\right) t_{N R}\right]
$$

$\mathrm{F}-\mathrm{HMIPv} 6$ 의 경우는 FMIPv6의 수식에서 $t_{U}$ 는 $t_{U}^{L}$ 로 $t_{N R}$ 는 $t_{N R}^{L}$ 로 변경하여 사용한다.

$\mathrm{MIPv6}$ 와 HMIPv6의 경운 핸드오버 시 터널링을 사용하 지 않으므로 $P_{s}=0$ 으로 설정하여 $\mathrm{MIPv6}$ 와 HMIPv6의 필 요한 버퍼 공간 크기를 구할 수 있다.

FPMIPv6의 필요한 버퍼 공간의 크기는 FMIPv6의 수식 에서 $\mathrm{MN}$ 의 대한 프로시져 수행시간을 줄일 수 있으므로 $t_{I P}^{P}$ 를 생략하여 다음과 같이 정의 할 수 있다.

$$
B S_{F P M I P v 6}^{l}=\lambda_{p}\left[P_{s} \cdot t_{L 2}+\left(1-P_{s}\right) t_{N R}\right]
$$

3.6 핸드오프 지연에 따른 패킷 손실

앞서 패킷 전송 비용을 계산하기 위해 핸드오프 지연에 관한 변수들을 정의하였다. $t_{L 2}, t_{D A D}, t_{R D}$ 등이 있는데 그 외에도 노드 $\mathrm{X}$ 에서 $\mathrm{Y}$ 로 전송하는 메시지의 지연은 $t_{X, Y}$ 로 정의하고 수식은 다음과 같다.

$$
t_{X, Y}(s)=\frac{1-q}{1+q} \frac{s}{B_{w l}}+L_{w l}+\left(d_{X, Y}-1\right) \frac{s}{B_{w}}+L_{w}+\varpi_{q}
$$

$q$ 는 무선 네트워크의 전송 실패 확률, $\varpi_{q}$ 는 인터넷의 각 라우터의 평균 큐잉(queueing)의 지연을[18], $B_{w l}, L_{w l}$ 은 무선 네트워크의 대역폭(bandwidth)과 링크 지연을 나타낸 상수이다. $\left(B_{w}, L_{w}\right.$ 는 유선 네트워크)

$$
D_{M I P v 6}=t_{L 2}+t_{R D}+t_{D A D}+t_{R R}+2\left(t_{M N, H A}+t_{M N, C N}\right)
$$

$\mathrm{HMIPv6}$ 의 경우 HA대신 MAP을 사용하므로 MIPv6 핸 드오프 지연 수식에서 $t_{R R}$ 과 $t_{M N, C N}$ 값을 무시한다

$\mathrm{FMIPv6}$ 와 F-HMIPv6 핸드오프 지연 수식은 다음과 같다.

$$
O_{F M I P v 6}^{l}=O_{F H M I P v 6}^{l}=\Delta_{n s}+t_{L 2}+2 t_{M N, N A R}
$$

$\Delta_{n s}$ 는 L2에서 핸드오프가 수행되기 전에 FBAck의 메시 지를 수신했을 때 까지의 시간을 의미한다. 만약 FBAck 메 시지가 이전에 링크를 통해 수신이 되지 않는 경우 FMIPv6 는 Reactive 모드가 수행되지만 F-HMIPv6의 경우는 $\mathrm{HMIPv6}$ 의 절차를 수행한다. FMIPv6의 핸드오프 지연 수식 은 다음과 같다.

$$
N_{F M I P v 6}^{l}=\Delta_{l r}+t_{L 2}+2 t_{M N, N A R}+3 t_{N A R, P A R}
$$

$\Delta_{l r}$ 은 FBAck의 메시지 수신 후 L2 핸드오프 시작 후 마지막 패킷을 수신할 때까지의 시간을 의미한다. 위의 두 수식을 통해 FMIPv6의 평균 핸드오프 지연 수식은 다음 과 같다.

$$
D_{F M I P v 6}^{l}=P_{s} O_{F M I P v 6}^{l}+\left(1-P_{s}\right) N_{F M I P v 6}^{l}
$$

위의 식을 통해 $\mathrm{F}-\mathrm{HMIPv} 6$ 의 평균 핸드오프 지연 수식도 정의할 수 있다.

그 다음으로 패킷 손실을 구하는 방법에는 버퍼관리 기능 의 유무에 따라 다음과 같이 분류할 수 있다.

$$
\begin{aligned}
& P_{\text {loss }}^{\text {scheme }, l}=\max \left(B S_{\text {scheme }}^{l}-B, 0\right) \\
& P_{\text {loss }}^{\text {scheme }, l}=\lambda_{p} D_{\text {scheme }}^{l}
\end{aligned}
$$

(26)의 수식에서 위의 수식은 버퍼 관리 기능이 있을 경 우 사용하고 아래의 수식은 버퍼 관리 기능이 없을 경우 적 용한다.

$\mathrm{PMIPv6}$ 는 MIPv6의 수식에서 $\mathrm{MN}$ 의 프로시져 수행시간 을 생략할 수 있으므로 다음과 같이 정의한다.

$$
D_{P M I P v 6}=t_{L 2}+t_{R D}+2 t_{M A G, L M A}
$$

FPMIPv6 핸드오프 지연 수식은 다음과 같다.

$$
O_{F P M I P v 6}^{l}=t_{L 2}
$$


PHI(Proxy Handover Initiate)/PHAck(Proxy Handover Acknowledgment) 메시지가 이전에 링크를 통해 수신이 되 지 않는 경우, FPMIPv6는 Reactive 모드를 수행한다. FPMIPv6의 핸드오프 지연 수식은 다음과 같다.

$$
N_{F P M I P v 6}^{l}=t_{L 2}+3 t_{p M A G, n M A G}+2 t_{n M A G, L M A}
$$

위의 두 수식을 통해 FPMIPv6의 평균 핸드오프 지연 수 식은 다음과 같다.

$$
D_{F P M I P v 6}^{l}=P_{s} O_{F P M I P v 6}^{l}+\left(1-P_{s}\right) N_{F P M I P v 6}^{l}
$$

\section{4. 성능 분석}

성능분석을 위해 필요한 추가 매개변수는 Table 3 과 같 이 정의한다.

Table 3. Parameters for the system performance analysis

\begin{tabular}{|c|c|c|}
\hline 기호 & 값 & 매개변수 \\
\hline$t_{D A D}$ & $500 \mathrm{~ms}$ & $\mathrm{DAD}$ 프로시져 지연시간 \\
\hline$t_{R D}$ & $100 \mathrm{~ms}$ & 라우터 발견에 따른 지연시간 \\
\hline$t_{L 2}$ & $50 \mathrm{~ms}$ & L2 핸드오프 지연시간 \\
\hline$P_{S}$ & 0.9 & 핸드오프 예측률 \\
\hline$q$ & 0.5 & 무선 연결 실패확률 \\
\hline$B_{w}$ & $100 \mathrm{Mbps}$ & 유선 연결 대역폭 \\
\hline$B_{w l}$ & $11 \mathrm{Mbps}$ & 무선 연결 대역폭 \\
\hline$L_{w}$ & $2 \mathrm{~ms}$ & 유선 연결 지연시간 \\
\hline$L_{w l}$ & $10 \mathrm{~ms}$ & 무선 연결 지연시간 \\
\hline$M$ & 2 & LMA(MAP)의 MAG(AR) 수 \\
\hline$S_{c}$ & $96 \mathrm{bytes}$ & 컨트롤 패킷 사이즈 \\
\hline$S_{d}$ & $200 \mathrm{bytes}$ & 데이터 패킷 사이즈 \\
\hline$\lambda_{p}$ & $10 \mathrm{packets/s}$ & 패킷 도착률 \\
\hline$v$ & $5.6 \mathrm{Km} / \mathrm{h}$ & MN의 평균 이동속도 \\
\hline$R$ & $500 \mathrm{~m}$ & 서브넷 경계 반지름 \\
\hline
\end{tabular}

이동성관리 분석을 위한 네트워크 모델은 Fig. 16 과 같다. $\mathrm{MN}$ 과 $\mathrm{MAG}(\mathrm{AR})$ 의 거리를 (a), $\mathrm{MAG}(\mathrm{AR})$ 과 $\mathrm{LMA}(\mathrm{MAP})$ 의 거리를 (b), $\mathrm{MAP}$ 과 $\mathrm{HA}$ 의 거리를 (C), $\mathrm{LMA}(\mathrm{MAP})$ 과 $\mathrm{CN}$ 의 거리를 (d), $\mathrm{LMA}(\mathrm{MAP})$ 과 $\mathrm{LMA}(\mathrm{MAP})$ 의 거리를 (e), HA와 $\mathrm{CN}$ 의 거리를 (f)로 정의하고 각 거리에 대한 수치는 (a) = 1 , (b) $=2$, (C) = (d) = (e) = (f) $=10$ 으로 정의한다.
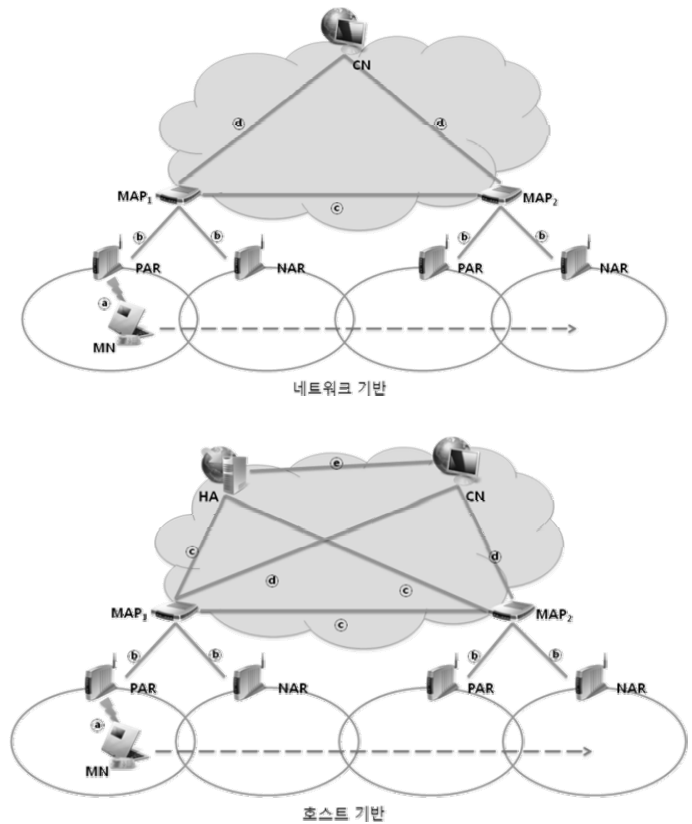

Fig. 16. Network topology used for analysis

Fig. 17은 각 프로토콜마다 SMR 변화에 따른 총 시그널 링 비용의 변화를 나타낸 그래프이다. SMR이 작을수록 이 동성 비율이 세션 도착률 보다 큰 것을 나타내는데 그래프 에서 볼 수 있듯이 전체적으로 $\mathrm{SMR}$ 이 1보다 크면(세션 도 착률이 이동성 비율보다 클 경우) 바인딩 업데이트가 덜 수 행되는 것을 알 수 있다. 또한 호스트 기반의 프로토콜보다 네트워크 기반의 프로토콜이, 기존의 표준 프로토콜보다 빠 른 핸드오프 프로토콜 (FMIPv6, F-HMIPv6, FPMIPv6)의 바인딩 업데이트가 덜 발생하는 것을 알 수 있다.

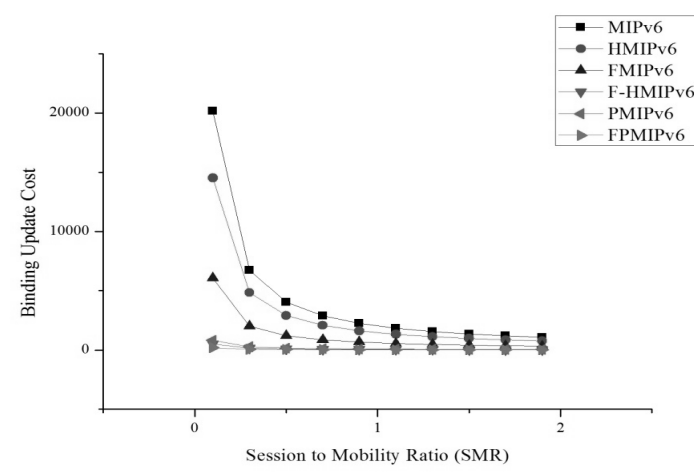

Fig. 17. Signaling costs in accordance with the SMR

Fig. 18은 패킷 도착률에 따른 패킷 전달 비용의 변화를 나타낸 그래프이다. 패킷 도착률에 변화에 따라 패킷 전달 비용이 비례하게 증가하는 것을 확인할 수 있었고 패킷 전 달 비용이 증가하게 되면 패킷 손실이 높아지므로 빠른 핸 드오프 프로토콜의 비용 증가가 상대적으로 적은 것으로 보 아 일정하고 높은 속도의 패킷을 요구하는 실시간 애플리케 이션에 적합한 것을 확인할 수 있었다. 


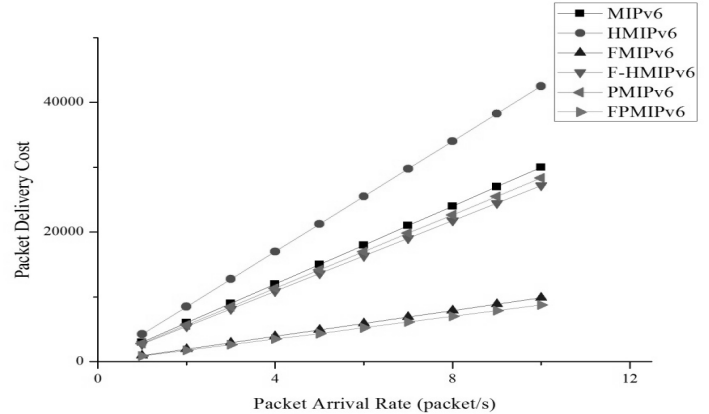

Fig. 18. The cost of delivering packets according to the packet arrival rate

Fig. 19는 핸드오프 예측 변화에 따른 패킷 전달 비용의 변화를 나타낸 것이다. Predictive 모드를 가지고 있는 FMIPv6와 F-HMIPv6, FPMIPv6에 대해 $P_{s}=0$ 일 때는 FMIPv6는 MIPv6와 같이 F-HMIPv6는 HMIPv6, FPMIPv6 같고 이는 $\mathrm{MAP}$ 의 추가적인 패킷 처리로 인해 패킷 전송을 위한 추가적인 비용이 있기 때문에 패킷 전달 비용이 변화 하는 것을 알 수 있다. 빠른 핸드오프 프로토콜에 대해 부 정확한 예측율을 줄이고 패킷 처리에 대한 프로세스를 개선 한다면 네트워크 기반의 프로토콜보다 좋은 결과를 얻을 수 있을 것이다.

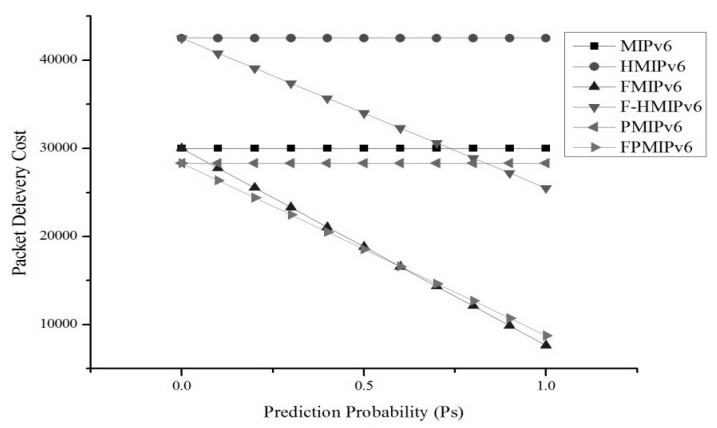

Fig. 19. Packet delivery cost according to handoff prediction probability

Fig. 20은 패킷 도착률에 따른 버퍼 공간의 변화를 나타 낸 것이다. 빠른 핸드오프 방식은 패킷 손실을 완화하기 위 해 패킷 버퍼링 기능을 지원하는데 그러기 위해서는 기존의 핸드오프 방식에 비해 상대적으로 더 많은 버퍼 공간을 필 요로 하는 것을 알 수 있다. 하지만 핸드오프가 수행되는 동안 엔드 투 엔드 지연(end-to-end delay)시간보다 더 긴 시간 동안 버퍼에서 패킷을 버퍼링한다면 신호전달 지연을 최소화 할 수 있으므로 $\mathrm{QOS}$ 를 제공하기 위해 효율적으로 버퍼를 관리하는 기능이 중요하다.

Fig. 21은 무선링크 지연에 따른 핸드오프 지연의 변화를 나타낸 것이다. 상대적으로 네트워크 기반 프로토콜이 호스 트 기반 프로토콜 보다 핸드오프 지연이 적은 것을 알 수 있었고 호스트 기반 프로토콜 중 빠른 핸드오프 프로토콜에 비해 MIPv6와 HMIPv6의 대기시간이 높은 결과로 보아

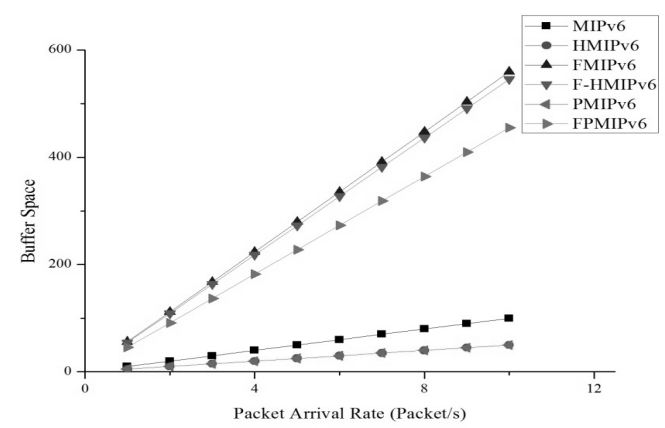

Fig. 20. The buffer space according to the packet arrival rate

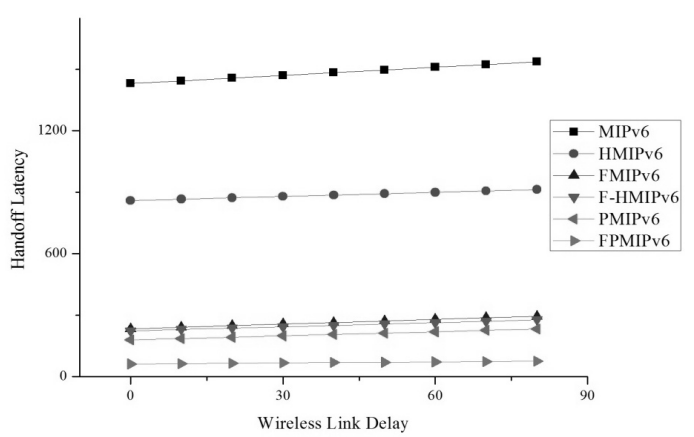

Fig. 21. Handoff delay according to the wireless link delay

$\mathrm{DAD}$ 프로시져 수행 시 발생하는 $\mathrm{DAD}$ 프로시져 지연시간 이 핸드오프 지연에 많은 영향을 주는 것으로 알 수 있었다.

\section{5. 결 론}

이동성관리는 차세대 무선 네트워크와 $4 \mathrm{G}$ 무선 네트워크 에서 핵심적인 문제이다. 몇몇의 IPv6기반의 이동성관리 기 법들이 IETF에서 제안되었지만 그 기법들은 실시간 어플리 케이션이나 특별히 중요한 어플리케이션에 대해 완벽한 로 밍과 연속적인 서비스 지원을 보장할 수 없는 상태이다. 위 의 프로토콜들의 분석 방법은 시뮬레이션에 따라 성능 평가 가 다르게 나타난다. 좀 더 정형화 된 수치결과와 전반적인 심도 있는 성능 분석을 제공하기 위해 본 논문은 IPv6 기반 의 분석 모델을 제안하였고 패킷 전달 비용, 핸드오프 지연 및 패킷 손실율 측면에서 사용자의 이동성 및 트래픽 모델 을 바탕으로 분석하였다. 분석 모델들을 통해 SMR, 핸드오 프 예측율, 무선 연결 지연과 같은 매개변수들이 $\mathrm{MN}$ 의 이 동성과 트래픽에 미치는 효과를 알 수 있었으며 무선 네트 워크 설계를 용이하게 하는 데에 많은 도움이 되었고 성능 평가를 통해 얻어낸 수치 결과들은 IETF에 의해 제안된 기 법들에 대해 잠재적인 장단점을 보여주었다. 그 중에서도 FPMIPv6 기법은 다른 프로토콜보다 핸드오프 지연 및 패 킷 손실에 대해 개선이 가능할 수 있음을 알 수 있었다. 하 지만 FPMIPv6가 차세대 무선 네트워크와 4G 무선 네트워 크에서 IPv6 기반의 이동성 프로토콜을 지배할 수 있을 것 
이라고 예측하기는 어렵다. 현재도 많은 프로토콜들이 제안 되고 있지만 이러한 프로토콜들을 비교, 분석하기 위해 좀 더 많은 노력이 필요할 것이다. 이동성관리 기법의 선택은 성능 기준에 따르지만 그것이 비용과 이익 측면만 내세울 점은 아니라는 것이며 이상적인 이동성관리 프로토콜을 설 계하고 배포할 때까지 모바일 사용자들은 여전히 실용적인 솔루션을 필요로 할 것이다.

앞으로 다른 네트워크 기술들간의 통합과 네트워크간 상호 운용성 등의 아직 해결되지 않은 연구분야를 확장하여, 이종의 모바일 환경에서 완벽하고 끊김이 없는 이동성을 제공하기 위 한 연구를 진행할 것이다. 또한, QoS(Quality of Service)의 지 원, 보안과 다른 표준들간의 상호작용 등은 효율적인 이동성관 리 프로토콜을 설계하기 위해서는 반드시 필요하기 때문에 지 속적으로 연구의 범위를 확대해 나갈 계획이다.

\section{참 고 문 헌}

[1] I. F. Akyildiz, S. Mohanty, and J. Xie, "A ubiquitous mobile communication architecture for next-generation heterogeneous wireless systems", IEEE Commun. Mag., Vol.43, No.6, pp.29-36, June, 2005.

[2] D. B. Johnson, C. E. Perkins, and J. Arkko, "Mobility support in IPv6", IEFT RFC 3775, June, 2004.

[3] G. Koodli, "Fast handovers for mobile IPv6", IETF RFC 4068, July, 2005.

[4] H. Soliman, C. Castelluccia, K. El-Malki, and L. Bellier, "Hierarchical mobile IPv6 mobility management (HMIPv6)", IETF RFC 4140, Aug., 2005.

[5] X. P'erez-Costa, M. Torrent-Moreno, and H. Hartenstein, "A performance comparison of mobile IPv6, hierarchical mobile IPv6, fast handovers for mobile IPv6 and their combination", ACM Mobile Computing and Commun. Rev., Vol.7, No.4, pp.5-19, Oct., 2003.

[6] Y. Gwon, J. Kempf, and A. Yegin, "Scalability and robustness analysis of mobile IPv6, fast mobile IPv6, hierarchical mobile IPv6, and hybrid IPv6 mobility protocols using a large- ${ }^{-}$scale simulation", in Proc. IEEE Int. Conf. on Commun. (ICC'04), Vol.7, pp.4087-4091, June, 2004.

[7] J. Xie and I. F. Akyildiz, "A novel distributed dynamic location management scheme for minimizing signaling costs in mobile IP”, IEEE Trans. Mobile Computing, Vol.1, No.3, pp.163-175, July, Sept., 2002.

[8] X. P'erez-Costa, R. Schmitz, H. Hartenstein, and M. Leibsch, "A MIPv6, FMIPv6 and HMIPv6 handover latency study: analytical approach", in Proc. IST Mobile and Wireless Commun. Summit, pp.100-105, June, 2002.

[9] C. Castelluccia, "HMIPv6: a hierarchical mobile IPv6 proposal", ACM Mobile Computing and Commun. Rev., Vol.4, No.1, pp.48-59, Jan., 2000.

[10] S. Pack and Y. Choi, "Performance analysis of fast handover in mobile IPv6 networks", in Proc. IFIP Pers. Wireless Commun., LNCS, Vol.2775, pp.679-691, Sept., 2003.

[11] S. Pack and Y. Choi, "A study on performance of hierarchical mobile IPv6 in IP-based cellular networks", IEICE Trans. Commun., Vol.E87-B, No.3, pp.462-469, March, 2004.

[12] S. Thomson and T. Narten, "IPv6 stateless address autoconfiguration", IETF RFC 2462, Dec., 1998.

[13] K. D. Wong, A. Dutta, H. Schulzrinne, and K. Young, "Simultaneous mobility: analytical framework, theorems and solutions", Wireless Commun. and Mobile Computing (Wiley), to appear, July 18, 2005.

[14] H. Y. Jung, E. A. Kim, J.W. Yi, and H. H. Lee, "A scheme for supporting fast handover in hierarchical mobile IPv6 networks", ETRI Journal, Vol.27, No.6, pp.798-801, Dec., 2005.

[15] Y. Fang, "Movement-based mobility management and trade off analysis for wireless mobile networks", IEEE Trans. Computers, Vol.52, No.6, pp.791-803, June, 2003.

[16] F. V. Baumann and I. G. Niemegeers, "An evaluation of location management procedures", in Proc. 3rd Annual Int. Conf. Universal Personal Commun. (UPC'94), pp.359-364, Sept./Oct., 1994.

[17] R. Koodli and C. E. Perkins, "Fast handovers and context transfers in mobile networks", ACM Mobile Computing and Commun. Rev., Vol.31, No.5, Oct., 2001.

[18] J. McNair, I. F. Akyildiz, and M. D. Bender, "Handoffs for real-time traffic in mobile IP version 6 networks", in Proc. IEEE GLOBECOM, Vol.6, pp.3463-3467, Nov., 2001.

[19] S. Gundavelli, K. Leung, V. Devarapalli, K. Chowdhury, B. Patil, "Proxy Mobile IPv6", IETF RFC 5213, Aug., 2008.

[20] Yokota, H., Chowdhury, K., Koodli, R., Patil, B., and F.Xia, "Fast Handovers for Proxy Mobile IPv6", RFC 5949, Sept., 2010.

[21] C. Makaya and S. Pierre, "An analytical framework for performance evaluation of IPv6-based mobility management protocols", IEEE Transactions on Wireless Communications, Vol.7, No.3, pp.972 - 983, Mar., 2008.

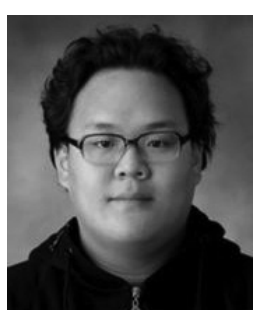

\section{원 영 훈}

e-mail : zzangwyh@hanmail.net 2005년 학점은행제(이학사)

2009년 현 재 성균관대학교 정보통신대학 석사과정

관심분야: 모바일컴퓨팅, Proxy Mobile IPv6, 네트워크 보안 등

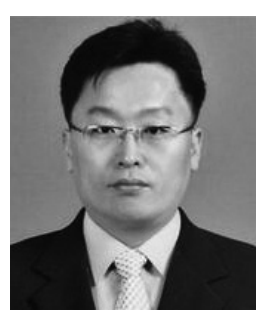

\section{정 종 필}

e-mail : jpjeong@ece.skku.ac.kr 2008년 성균관대학교 정보통신대학 (공학박사)

2009년 성균관대학교 컨버전스연구소 연구교수

2010년 현 재 성균관대학교 산학협력단 산학협력중점교수

관심분야: 모바일컴퓨팅, 센서 이동성, 차량 모바일 네트워크, 스마트기기 보안, 네트워크 보안, IT융합, 인터랙션 사이언스 등 